\title{
Al-doped magnetite encapsulated in mesoporous carbon: A long-lasting Fenton catalyst for CWPO of phenol in a Fixed-bed reactor at mild conditions
}

\author{
K. Thirumoorthy ${ }^{a}$, B. Gokulakrishnan ${ }^{a}$, G. Satishkumar ${ }^{a *}$, M.V. Landau ${ }^{b}$, M. Wong Chi Man ${ }^{c}$ and E. Oliviero ${ }^{c}$
}

\author{
${ }^{a}$ Advanced Materials and Catalysis Lab, Department of Chemistry, School of Advanced Sciences, Vellore \\ Institute of Technology, Vellore-632014, Tamilnadu, India. Tel: +91-416-2202714. E-mail: \\ satishkumar.g@vit.ac.in; satishgsamy@gmail.com. \\ ${ }^{b}$ Blechner Center for Industrial Catalysis and Process Development, Department of Chemical Engineering, \\ Ben-Gurion University of the Negev, Beer-Sheva, 84105, Israel \\ c ICGM University of Montpellier, CNRS, ENSCM, Montpellier, France
}

\section{Abstract}

Al-doped magnetite spinel nanoparticles encapsulated in mesoporous carbon (MC) were identified as promising heterogeneous Fenton catalyst towards phenol degradation in continuous system for practical applications. At the working conditions inside the fixed-bed reactor hercynite in the fabricated $21 \% \gamma-\mathrm{Fe}_{2} \mathrm{O}_{3} / 28 \% \mathrm{FeAl}_{2} \mathrm{O}_{4} @ \mathrm{MC}$ material reacts with $\mathrm{H}_{2} \mathrm{O}_{2}$. In this reaction $\mathrm{Al}$ ions occupied the vacant octahedral cationic sites in the framework of $y$ - $\mathrm{Fe} 2 \mathrm{O} 3$ component converting it to $\mathrm{Al}$ substituted magnetite spinel. The $\mathrm{Al}$ in the obtained $\mathrm{Fe}^{3+}{ }_{0.66} \mathrm{Fe}^{2+}{ }_{0.33}\left(\mathrm{Fe}^{2+}{ }_{0.33} \mathrm{Fe}^{3+}{ }_{0.33} \mathrm{Al}^{3+}{ }_{0.33}\right)_{2} \mathrm{O}_{4} @ \mathrm{MC}$ polarizes electrons of iron ions through its Lewis acid property imparting more positive charge on iron ions $\left(\mathrm{Fe}^{\mathrm{n}+(\delta+)}\right)$. This expedites the rate of the challenging reduction reaction $\mathrm{Fe}^{3+} \rightarrow \mathrm{Fe}^{2+}$ with $\mathrm{H}_{2} \mathrm{O}_{2}$ to produce $\mathrm{HOO}^{\prime}$ and reinforce the bonding of iron ions in the spinel improving their activity and stability. Hence, at the mild operating conditions $\left(\mathrm{pH} 5,40^{\circ} \mathrm{C}, 8.6 \mathrm{mlwater} / \mathrm{mlcat} * \mathrm{~h}, 0.036 \mathrm{~mol}_{2} \mathrm{O}_{2}, 200 \mathrm{ppm}\right.$ phenol) the in situ produced catalyst $\mathrm{Fe}\left(\mathrm{Fe}_{0.66} \mathrm{Al}_{0.33}\right)_{2} \mathrm{O}_{4} @ \mathrm{MC}$ of $35 \mathrm{~nm}$ containing $19.9 \% \mathrm{Fe}$ and 2.4\%Al with surface area of $335 \mathrm{~m}^{2} / \mathrm{g}$ exhibited long-lasting high catalytic activity and stability in $500 \mathrm{~h}$ run. $80 \%$ TOC conversion and $\sim 1 \mathrm{ppm}$ of leached Fe in treated water were obtained without visible changing of catalytic performance.

\section{Introduction}

Various treatment methods involving physical, chemical and biological processes such as adsorption, ozonation, aerobic/anaerobic biodegradation etc. have been adapted for the removal of pollutants from the industrial wastewater before it is discharged into the environment. ${ }^{1}$ Fenton process known as catalytic wet peroxide oxidation (CWPO) has been widely investigated for the oxidative degradation - mineralization of various organic pollutants. ${ }^{2}$ It catalytically decomposes hydrogen peroxide oxidant using soluble iron salt as a homogeneous catalyst selectively producing $\mathrm{HO}^{*}$ and $\mathrm{HO}_{2}{ }^{\circ}$ by which can effectively oxidize a wide range of organic pollutants. ${ }^{3}$ However, this method accompanies the downsides such as corrosive acidic condition, narrow $\mathrm{pH}$ range of operation and tedious procedure to separate the dissolved iron salt make its heterogeneous counterpart as a viable alternate. It was concluded that at relatively high $\mathrm{pH}$ where dissolution of iron oxides is negligible the selective decomposition of $\mathrm{H}_{2} \mathrm{O}_{2}$ forming $\mathrm{HO}^{\circ}$ and $\mathrm{HO}_{2}{ }^{\circ}$ radicals may proceed as a surface -catalysed process. ${ }^{4}$ It has been suggested that $\mathrm{H}_{2} \mathrm{O}_{2}$ decomposition proceeds through a chain reaction that is analogous to the $\mathrm{Fe}^{3+}$ initiated decomposition of $\mathrm{H}_{2} \mathrm{O}_{2}$ proposed by Haber and Weiss for homogeneous Fenton process. ${ }^{5}$ 
Customarily, Fe-based solid materials (individual and supported iron oxides) have been engaged as heterogeneous Fenton catalysts to degrade various pollutants through CWPO in batch ${ }^{6,7}$ and more practical continuous reactors. ${ }^{8-29}$ However, it was observed that catalysts exhibit low activity in degradation of less reactive pollutants like phenols and lag in their activity with increasing of the run time owing to leaching of metal ions. It should be noted that efficiency of heterogeneous Fenton catalysts depends on regeneration of $\mathrm{Fe}^{2+}$ (i.e. reduction of $\mathrm{Fe}^{3+}$ to $\mathrm{Fe}^{2+}$ ) as well and is the rate determine step in the Fenton process (Scheme 1). ${ }^{30-32}$ Based on these considerations the efficient solid Fenton catalyst should be a high surface area porous material containing nanoparticles of iron oxides (mixed oxides) that include both $\mathrm{Fe}^{2+}$ and $\mathrm{Fe}^{3+}$ ions at its surface maximally accessible to water environment. The surface iron ions in Fe-oxide solids are strongly bonded to their neighbours compared with their hydrated counterparts in solution. Therefore, their reactivity in chain tractions shown in Scheme 1 is significantly lower. To increase the reactivity, the coordination and electronic environment of surface ions in solid Fenton catalysts should be modified by doping with promoters.

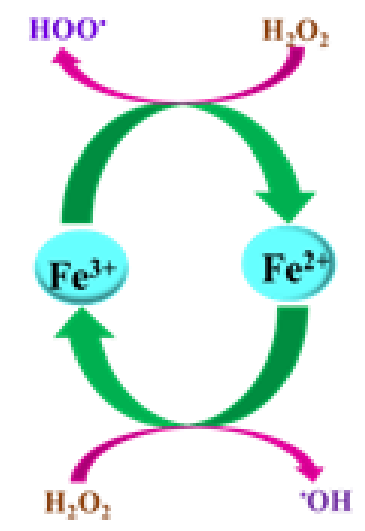

Scheme 1. $\mathrm{H}_{2} \mathrm{O}_{2}$ decomposition mechanism

Alumina $\left(\mathrm{Al}_{2} \mathrm{O}_{3}\right)$ was found to be an efficient catalyst support which significantly enhances the catalytic activity and stability of iron oxide particles in CWPO by Fe-Al interactions. ${ }^{32}$ The $\mathrm{Fe} / \mathrm{V}-\mathrm{Al}_{2} \mathrm{O}_{3}$ catalyst demonstrated remarkable stability in long-term continuous experiments over $100 \mathrm{~h}$ time on stream of phenol $\mathrm{CWPO}$ at $50{ }^{\circ} \mathrm{C}, \mathrm{pH}=3$ with phenol and $\mathrm{TOC}$ reductions close to 100 and $50 \%$, respectively. ${ }^{33}$ The results reported in ${ }^{34}$ showed that the $\mathrm{Fe}_{3} \mathrm{O}_{4} / \mathrm{\gamma}-\mathrm{Al}_{2} \mathrm{O}_{3}$ catalyst demonstrates about three times faster decomposition of $\mathrm{H}_{2} \mathrm{O}_{2}$ than $\mathrm{Fe}_{2} \mathrm{O}_{3} / \mathrm{Y}-\mathrm{Al}_{2} \mathrm{O}_{3}$ leading to an increased degradation and mineralization of 2,4,6-trichlorophenol stable for $100 \mathrm{~h}$ on stream. At the optimized conditions $\left(\mathrm{T}=80^{\circ} \mathrm{C},\left[\mathrm{H}_{2} \mathrm{O}_{2}\right]:[\mathrm{Phenol}]=16.8\right)$ the highly dispersed $\mathrm{Fe}^{3+}-\mathrm{Al}_{2} \mathrm{O}_{3}$ catalyst retained high TOC conversion of ca $70 \%$ for $70 \mathrm{~h}$ of stream with iron content in the effluent $<10 \mathrm{ppm} .{ }^{11} \mathrm{Lim}$ et al. postulated that besides serving as support, alumina through its Lewis acid property can attract electron density around the $\mathrm{Fe}^{3+}$ and facilitate challenging reduction of $\mathrm{Fe}^{3+}$ to $\mathrm{Fe}^{2+}$ by $\mathrm{H}_{2} \mathrm{O}_{2}{ }^{35}$ Likewise, it was observed that mixed silica-alumina-iron oxide catalyst exhibited higher stoichiometric efficiency (moles of phenol transformed per mole of $\mathrm{H}_{2} \mathrm{O}_{2}$ ) compared with the corresponding iron oxide. ${ }^{36}$ Thus, aluminium may serve as an efficient promoter for solid Fenton catalysts. Further research is required to understand the role of $\mathrm{Al}$ in facilitating the heterogeneous Fenton reaction.

In that respect, instead of utilizing the Al function as support for Fe-oxide nanoparticles it was envisioned that substituting $\mathrm{Al}$ for $\mathrm{Fe}$-ions in the lattice of $\mathrm{Fe}_{3} \mathrm{O}_{4}$ spinel and encapsulating it inside the mesoporous graphitic carbon support would be a perspective strategy to acquire active and stable catalyst in CWPO of pollutants. It is expected that doped Al in the lattice of magnetite spinel can 
effectively polarize the electrons of whole Fe ions in the spinel structure through its Lewis acid property attracting electron density around the $\mathrm{Fe}^{3+}$ and facilitating the challenging reduction of $\mathrm{Fe}^{3+}$ to $\mathrm{Fe}^{2+}$ by $\mathrm{H}_{2} \mathrm{O}_{2}$. The donor-acceptor interaction between $\mathrm{Al}$ - and $\mathrm{Fe}$-ions in the spinel structure would strengthen the Fe bonding in the mixed oxide reducing its leaching in CWPO process. Moreover, supporting of Aldoped magnetite on mesoporous carbon (MC) instead alumina may significantly improve the catalytic activity. Graphitic layers can facilitate reduction of $\mathrm{Fe}^{3+}$ to $\mathrm{Fe}^{2+}$ donating electrons from delocalized $\pi$ electrons at the oxide-carbon interface. ${ }^{37}$ Mesopores of the carbon matrix with hydrophobic walls facilitate the organic pollutant molecules to be adsorbed at the close vicinity of the Al doped magnetite catalyst, thus, enhancing their degradation rate significantly.

However, synthesising Al substituted magnetite by co-precipitation method and subsequent encapsulation in the mesoporous graphitic carbon matrix not only involve complex multistep synthesis procedure but also would disrupt the spinel composition. In this respect application of the emerging facile approach of utilizing metal organic frameworks (MOFs) as templates/precursors to construct metal oxide encapsulated porous carbon may be very productive. The fabrication of proposed hybrid Al-magnetite -carbon heterogeneous Fenton catalyst by this method is promising as it does not involve multistep procedure to prepare core metal oxide and its coating with carbon shell. ${ }^{38-40}$ Initially, $\mathrm{Fe}_{3} \mathrm{O}_{4} / \mathrm{Fe}^{0} @ \mathrm{MC}$ composite was obtained by catalytic carbonization of Fe-MOF followed by loading of aluminium precursor into the mesopores of carbon matrix led to formation of $\gamma-\mathrm{Fe}_{2} \mathrm{O}_{3} / \mathrm{FeAl}_{2} \mathrm{O}_{4} @ \mathrm{MC}$. In situ transformations of composition and structure of $\gamma-\mathrm{Fe}_{2} \mathrm{O}_{3} / \mathrm{FeAl}_{2} \mathrm{O}_{4} @ \mathrm{MC}$ material at the beginning of CWPO run forms stable composition of $\mathrm{Fe}\left(\mathrm{Fe}_{0.66} \mathrm{Al}_{0.33}\right)_{2} \mathrm{O}_{4} @ \mathrm{MC}$ catalyst where $\mathrm{Fe}\left(\mathrm{Fe}_{0.66} \mathrm{Al}_{0.33}\right)_{2} \mathrm{O}_{4}$ is an Al-substituted Fe-Al-O spinel.

Herein we report the structure, state of iron and remarkable catalytic activity and stability of a novel catalytic material - Al substituted magnetite encapsulated in MC towards CWPO of phenol as model pollutant in a fixed-bed reactor. Disodium terephthalate utilized as a ligand source to synthesise Fe-MOF was derived by environment-friendly method from used waste polyethylene terephthalate (PET) bottles flakes. Fabricated composites were extensively characterized using XRD, $\mathrm{N}_{2}$ adsorptiondesorption, TGA, SEM-EDAX, STEM-EDX and XPS techniques. Testing experiments were performed in the fixed-bed reactor using phenol as a model pollutant at mild operating conditions varying reaction parameters like temperature, $\mathrm{pH}, \mathrm{H}_{2} \mathrm{O}_{2}$ concentration and flow rate to accomplish high activity and stability of developed catalysts.

\section{Experimental}

Materials and Characterization methods

The detail of the chemicals used in this study and characterization methods-XRD (Rietveld refinement), TGA, BET, FE-SEM, HR-TEM, XPS, TOC, AAS, ICP-OES, and UPLC are available in the supplementary materials.

\section{Synthesis of Fe-MOF}

Disposed of PET bottles with average molecular weight 27400 , melting point $255^{\circ} \mathrm{C}$, carbon content $62.3 \%$ were collected, washed, dried and used after removal of the polyethylene caps and the polypropylene label..$^{41}$ Initially, depolymerisation of waste PET into disodium terephthalate salt was carried out in an aqueous alkaline medium by following the procedure reported in the literature with minor amendments. ${ }^{42}$ Briefly, $3 \mathrm{~g}$ of ca $6 \mathrm{~mm}$ size waste PET bottles flakes was transferred to $100 \mathrm{ml}$ Teflon-lined stainless-steel autoclave containing $50 \mathrm{ml}$ of $4.5 \mathrm{~N} \mathrm{NaOH}$ solution. The autoclave was heated at $200{ }^{\circ} \mathrm{C}$ for $2 \mathrm{~h}$ and brought to room temperature. The precipitated disodium terephthalate was filtered using $\mathrm{G} 4$ glass filter with pore size of 5-15 microns fitted with $250 \mathrm{ml}$ conical flask and dried 
at temperature of $100{ }^{\circ} \mathrm{C}$ overnight in a hot air oven (95\% yield). For Fe-MOF synthesis, $0.83 \mathrm{~g}(4 \mathrm{mmol})$ of the obtained disodium terephthalate salt was dissolved in $200 \mathrm{ml}$ of water in the $500 \mathrm{ml}$ reagent

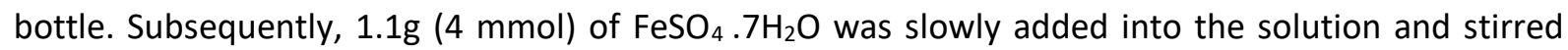
using Teflon oval egg shaped magnetic stir bar (700 RPM) for 12 hours at room temperature. After closing the reagent bottle with screw cap, the whole solution was kept in a hot air oven for about an hour at $60^{\circ} \mathrm{C}$ till Fe-MOF is formed and settled at the bottom. Then, the filtrate solution was decanted and obtained Fe-MOF was washed multiple times with water to remove the sodium and sulphate ions.

\section{Fabrication of $\gamma-\mathrm{Fe}_{2} \mathrm{O}_{3} / \mathrm{FeAl}_{2} \mathrm{O}_{4} @ M C$ and Graphitic $\mathrm{MC}$}

Preliminary experiments were performed looking for optimal values of parameters selected for synthesis of prepared materials. The procedures of encapsulation of iron oxide inside carbon matrix using Fe-MOF precursor and generation of mesopores in the carbon matrix through carbothermal reduction described in details elsewhere. ${ }^{39}$ Synthesised Fe-MOF has been carbonized at various temperatures $\left(700-750^{\circ} \mathrm{C}\right)$ and time $\left(10-30 \mathrm{~min}\right.$.) in nitrogen atmosphere at the heating rate of $5^{\circ} \mathrm{C} / \mathrm{min}$ using a tubular furnace. However, the resultant material lost more carbon matrix during the carbonization process consequently, the formed iron oxide ejected out of the remaining carbon matrix. Hence, sucrose has been used as an additional carbon source. Through various trials $1.9 \mathrm{~g}$ of sucrose was found to be optimum quantity which yields highly dispersed iron oxide encapsulate in the mesoporous carbon matrix. Thus, $0.5 \mathrm{~g}$ of Fe-MOF was added to a solution contains $5.7 \mathrm{mmol}(1.9 \mathrm{~g})$ of sucrose in $25 \mathrm{ml}$ of water. Later, $5 \mathrm{ml}$ of $0.05 \mathrm{~N}$ sulphuric acid was introduced into the solution and stirred at $80^{\circ} \mathrm{C}$ for $1 \mathrm{~h}$ then it was heated at $130^{\circ} \mathrm{C}$ for $6 \mathrm{~h}$ to obtain fully polymerized and carbonized sucrose. Optimum carbonization temperature required to accomplish the core-shell morphology of the material was found through TGA analysis of sucrose coated Fe-MOF and the thermal treatment time was optimized through multiple trials (detailed discussion available in characterization results of Fe-MOF chapter). $\mathbf{p}-\mathrm{Fe}_{2} \mathrm{O}_{3} / \mathrm{FeAl}_{2} \mathrm{O}_{4} @ \mathrm{MC}-\mathrm{The} \mathrm{Fe}_{3} \mathrm{O}_{4} / \mathrm{Fe}^{0} @ \mathrm{MC}$ composite was obtained by catalytic carbonization of above acquired material at $800{ }^{\circ} \mathrm{C}$ for $30 \mathrm{~min}$ in an inert atmosphere. Further, based on pore volume, insertion of the aluminium precursor (anhydrous $\left.\mathrm{Al}\left(\mathrm{NO}_{3}\right)_{3}\right)$ into the mesopores of carbon matrix was carried out through incipient wetness impregnation technique followed by thermal treatment at $550{ }^{\circ} \mathrm{C}$ for $1 \mathrm{~h}$ in an inert atmosphere to yield $\mathrm{\gamma}$ $\mathrm{Fe}_{2} \mathrm{O}_{3} / \mathrm{FeAl}_{2} \mathrm{O}_{4} @ \mathrm{MC}$ catalyst. Graphitic MC- $0.5 \mathrm{~g}$ of $\mathrm{Fe}_{3} \mathrm{O}_{4} / \mathrm{Fe}^{0} @ \mathrm{MC}$ was transferred into $100 \mathrm{ml}$ of $1 \mathrm{~N}$ hydrochloric and nitric acid mixture (3:1) in $250 \mathrm{ml}$ beaker and stirred for $12 \mathrm{~h}$ inside the fume hood to extract the iron. Subsequently, the solid carbon material is centrifuged and the above acid treatment is repeated for three times. Finally, the obtained carbon material is washed several times with distilled water and dried overnight.

\section{Synthesis of $\mathrm{FeAl}_{2} \mathrm{O}_{4}$ nanoparticles}

$\mathrm{FeAl}_{2} \mathrm{O}_{4}$ (hercynite) nanoparticles was prepared by following the procedure reported in the literature. ${ }^{43}$ $5 \mathrm{mmol}$ of $\mathrm{Fe}\left(\mathrm{NO}_{3}\right)_{3} \cdot 9 \mathrm{H}_{2} \mathrm{O}$ was mixed with $10 \mathrm{mmol}$ of $\mathrm{Al}\left(\mathrm{NO}_{3}\right)_{3} \cdot 9 \mathrm{H}_{2} \mathrm{O}, 15 \mathrm{mmol}$ of urea and $5 \mathrm{mmol}$ of diethylamine hydrochloride. Then the mixture was heated in muffle furnace for $10 \mathrm{~min}$ to get dark grey colored hercynite nanoparticles.

\section{Catalytic studies}

The performance of catalysts towards the degradation of phenol through CWPO was tested in an upflow fixed bed reactor shown in Fig. S2 similar to that used in reported literature. ${ }^{24}$ The tubular reactor was made of Teflon with reactor length $30 \mathrm{~cm}$, ID $0.8 \mathrm{~cm}$, packed bed $16 \mathrm{~cm}$ and catalysts layer $6-7$ $\mathrm{cm}$. The $100 \mathrm{mg}$ catalyst was mixed with $400 \mathrm{mg}$ of silica gel (100-200 mesh) yielding a total reaction volume of $0.7 \mathrm{~cm}^{3}$ and packed between ceramic beads to enable the inlet solution inside the catalyst bed with better distribution. Quartz wool plugs were kept at the inlet and outlet of catalyst layer to 
prevent the catalyst lost during the long testing runs. Typically, aqueous solution that contained 200 ppm phenol and stoichiometric amount $\left(\mathrm{S}=14 \mathrm{~mol} / \mathrm{mol}_{6} \mathrm{H}_{6} \mathrm{O}\right)$ of hydrogen peroxide $\left(\mathrm{C}_{6} \mathrm{H}_{5} \mathrm{OH}+\right.$ $14 \mathrm{H}_{2} \mathrm{O}_{2} \rightarrow 6 \mathrm{CO}_{2}+17 \mathrm{H}_{2} \mathrm{O}$ ) was fed to the reactor using peristaltic pump. The residence time in catalysts testing experiments was varied in range of $0.04-0.12 \mathrm{~h}$ corresponding to water flow rate $0.3-0.1$ $\mathrm{mL} / \mathrm{min}$, respectively. Samples of the treated effluent were periodically withdrawn to determine the TOC, phenol removal and leached iron and aluminium concentrations. TOC conversion was calculated by the following equation:

$$
\text { TOC } \%=\left(C_{0}-C\right) / C_{0} \times 100
$$

where $\mathrm{C}$ and $\mathrm{C}_{0}$ stand for TOC concentration of phenol before and after degradation, respectively. The catalyst layer was diluted with silica gel is stable and no catalyst loss was detected along with the liquid stream due to the presence of Quartz wool plugs at the inlet and outlet of catalyst layer. The total carbon balance was closed by $>95 \%$ comparing the total mass of the carbon in phenol entered the reactor with the mass of residual organic carbon remained in the reactor effluent measured by TOC analyzer and assuming that carbon not detected in the treated water as TOC was converted to $\mathrm{CO}_{2}$.

\section{RESULTS AND DISCUSSION}

\section{Characterization results of Fe-MOF and $\mathrm{p}-\mathrm{Fe}_{2} \mathrm{O}_{3} / \mathrm{FeAl}_{2} \mathrm{O}_{4} @ M C$}

Heterogeneous Fenton catalyst comprising low-cost materials like iron oxide and carbon support is ever preferred for the practical application. Moreover, the development of catalytic materials derived from waste materials makes the system more cost effective and environmentally benign. Synthesis of MOFs using domestic PET waste bottles (occupy large volume and take a long time to degrade) gains importance in recent years. ${ }^{41,44,45}$ Hence, it has been decided to use disodium terephthalate derived from used PET bottles flakes as ligand source to synthesise Fe based MOF. ${ }^{46}$ The sodium ions in the disodium terephthalate can be easily replaced by the iron ions thus, it can form Fe-MOF under the given synthesis condition.

The XRD pattern of synthesised Fe-MOF shown in Fig. S3 is in good agreement with XRD data reported for MOF material MIL-88B(Fe) ${ }^{46}$ having the surface area of $75 \mathrm{~m}^{2} / \mathrm{g}$ (Table 1 ). The FE-SEM and HR-TEM images of synthesised Fe-MOF displayed in Fig. S4 demonstrates that acquired particles bear spindlelike morphology with an average length of $200-300 \mathrm{~nm} .{ }^{47}$ It was observed that carbonization of FeMOF at various temperatures $\left(700-750^{\circ} \mathrm{C}\right)$ and time $(10-30 \mathrm{~min}$.) yields a composite material with less carbon content led to the ejection of formed iron oxide particles from the carbon matrix. Hence, an inexpensive carbon precursor sucrose was coated over the Fe-MOF as additional carbon source and FE-SEM image is shown in Fig. S5. Finding appropriate carbonization temperature and time is critical as it affords desired stable carbon matrix, mesopores and dispersed catalytic sites in the final material. Therefore, the thermogravimetric analysis was carried out for sucrose coated Fe-MOF under $\mathrm{N}_{2}$ atmosphere. The thermogram of sucrose coated Fe-MOF depicts four weight loss peaks at distinct temperatures (Fig. S6). Physically adsorbed and occluded water molecules in the Fe-MOF discharged at the first stage of weight loss $(15 \%)$ which extended up to $180{ }^{\circ} \mathrm{C}$. Owing to the thermal decomposition of Fe-terephthalate framework and sucrose substantial weight loss (59\%) happened in the second and third stages. The fourth weight loss (6\%) occurred due to the carbothermal reduction of iron oxide at high temperature between 700 to $800{ }^{\circ} \mathrm{C}$ provides the critical information for identification of essential carbonization temperature to accomplish the core-shell morphology $\mathrm{FeO}_{x} / \mathrm{Fe}^{0} @ \mathrm{MC}$.

After trialling carbonization process at the temperature range between 750 to $800{ }^{\circ} \mathrm{C}$, it was observed that sucrose coated Fe-MOF heated at $800{ }^{\circ} \mathrm{C}$ for 30 minutes had created a core-shell composite 
material $\mathrm{FeO}_{\mathrm{x}} / \mathrm{Fe}^{0} @ \mathrm{MC}$ with $\mathrm{MC}$ shell. The wide-angle XRD pattern of the obtained carbon composite material contains peaks correspond to $47.5 \% \mathrm{Fe}_{3} \mathrm{O}_{4}$ phase of $35 \mathrm{~nm}$ (JCPDS $82-1533$ ) and $52.5 \%$ of 40 $\mathrm{nm} \alpha-\mathrm{Fe}^{0}$ phase (JCPDS 87-0721) (Fig S3). The reduction of encapsulated iron oxide nanoparticles into metallic iron by reacting with amorphous carbon created cavities in the carbon matrix and increased the surface area and pore volume of $\mathrm{Fe}_{3} \mathrm{O}_{4} / \mathrm{Fe}^{0} @ \mathrm{MC}$ to $577 \mathrm{~m}^{2} / \mathrm{g}$ and $0.4 \mathrm{~cm}^{3} / \mathrm{g}$, respectively (Table 1). Interestingly, $\mathrm{Fe}_{3} \mathrm{O}_{4} / \mathrm{Fe}^{0} @ \mathrm{MC}$ exhibited type IV $\mathrm{N}_{2}$-adsorption isotherm with lower closure point, attributed to $\mathrm{H} 3$ type loop and $\mathrm{BJH}$ pore size distribution peak centred at $3.8 \mathrm{~nm}$. This confirms that formed cavities are mesoporous in nature (Fig. S7). ${ }^{48}$ Subsequent loading of anhydrous Aluminium nitrate into the mesopores of $\mathrm{Fe}_{3} \mathrm{O}_{4} / \mathrm{Fe}^{0} @ \mathrm{MC}$ carbon matrix and following thermal treatment at 550 ${ }^{\circ} \mathrm{C}$ led to the formation of $\mathrm{\gamma}-\mathrm{Fe}_{2} \mathrm{O}_{3} / \mathrm{FeAl}_{2} \mathrm{O}_{4} @ \mathrm{MC}$ composite material. XRD analysis endorses in the $\mathrm{\gamma}$ $\mathrm{Fe}_{2} \mathrm{O}_{3} / \mathrm{FeAl}_{2} \mathrm{O}_{4} @ M C$ the formation of $49.5 \%$ of maghemite- $\gamma-\mathrm{Fe}_{2} \mathrm{O}_{3}$ phase (JCPDS 89-5892) of $40 \mathrm{~nm}$ accompanied with $51.5 \%$ of $13 \mathrm{~nm}$ Hercynite- $\mathrm{FeAl}_{2} \mathrm{O}_{4}$ phase (JCPDS 34-0192) (Fig. S3). The deconvoluted XRD pattern is given in Fig. S8. It is important that, despite the establishment of $\mathrm{FeAl}_{2} \mathrm{O}_{4}$, $\gamma-\mathrm{Fe}_{2} \mathrm{O}_{3} / \mathrm{FeAl}_{2} \mathrm{O}_{4} @ \mathrm{MC}$ displayed the high surface area of $415 \mathrm{~m}^{2} / \mathrm{g}$, pore volume $0.26 \mathrm{~cm}^{3} / \mathrm{g}$ (Table 1) and wide hysteresis loop in $\mathrm{N}_{2}$-adsorption isotherms (Fig. S7) which corroborates the existence of mesopores in the carbon matrix. Upon thermal treatment, loaded aluminium nitrate decomposes to form alumina which in turn reacts with the metallic iron to produce $\mathrm{FeAl}_{2} \mathrm{O}_{4}$ through the possible reaction given in equation (2). ${ }^{49}$ Since the loading of aluminium is less than the content of encapsulated $\mathrm{Fe}_{3} \mathrm{O}_{4} / \mathrm{Fe}^{0}$, the remaining iron has been oxidized into $\mathrm{\gamma}-\mathrm{Fe}_{2} \mathrm{O}_{3}$ in the course of the solid-state reaction.

$$
0.25 \mathrm{Fe}_{3} \mathrm{O}_{4}+0.25 \mathrm{Fe}^{0}+\mathrm{Al}_{2} \mathrm{O}_{3} \longrightarrow \mathrm{FeAl}_{2} \mathrm{O}_{4} \quad \text { (Eq. 2) }
$$

Table 1 Physicochemical properties of synthesised catalytic materials

\begin{tabular}{|c|c|c|c|c|c|c|c|}
\hline \multirow{3}{*}{ sample } & \multirow{3}{*}{$\begin{array}{l}\text { Components } \\
\text { size }(\mathrm{nm})\end{array}$} & \multirow{3}{*}{$\begin{array}{l}\text { Total } \\
\text { surface } \\
\text { area } \\
\left(\mathrm{m}^{2} / \mathrm{g}\right)\end{array}$} & \multirow{3}{*}{$\begin{array}{c}\text { Pore } \\
\text { volume } \\
\text { (cc/g) }\end{array}$} & \multicolumn{4}{|c|}{ Elements weight \% } \\
\hline & & & & \multicolumn{2}{|c|}{ Theoretical } & \multicolumn{2}{|c|}{ ICP-OES } \\
\hline & & & & $\mathrm{Fe}$ & Al & $\mathrm{Fe}$ & Al \\
\hline Fe-MOF & - & 75 & 0.04 & - & - & - & - \\
\hline $\mathrm{Fe}_{3} \mathrm{O}_{4} / \mathrm{Fe}^{0} @ \mathrm{MC}$ & $35 / 40$ & 577 & 0.40 & - & - & - & - \\
\hline \multicolumn{8}{|l|}{$\gamma-\mathrm{Fe}_{2} \mathrm{O}_{3} /$} \\
\hline \multicolumn{8}{|l|}{$\mathrm{FeAl}_{2} \mathrm{O}_{4} @ \mathrm{MC}$} \\
\hline $\begin{array}{c}\mathrm{Fe}\left(\mathrm{Fe}_{0.68} \mathrm{Al}_{0.32}\right)_{2} \\
\mathrm{O}_{4} @ \mathrm{MC}\end{array}$ & 35 & 335 & 0.20 & 20.6 & 2.72 & 19.85 & 2.52 \\
\hline
\end{tabular}

FE-SEM image of $\gamma-\mathrm{Fe}_{2} \mathrm{O}_{3} / \mathrm{FeAl}_{2} \mathrm{O}_{4} @ M C$ together with EDAX data is given in Fig. 1a. Apparently, spindlelike morphology was ruined as the carbon formed from the supplement carbon source (sucrose) enveloped the spindles and led to the formation of big particles of up to $41 \mu \mathrm{m}$ size without definite morphology (Fig. S5(b)). The contents of Al and Fe in catalysts presented in Table 1 were calculated based on their amounts measured by ICP-OES analysis in solution obtained after extraction of Fe and Al from the catalyst. They were consistent with that obtained by EDAX analysis of solid catalyst averaging the results measured at five different points of catalysts particles (Fig.1a). Detailed calculation for the theoretical estimation of $\mathrm{Fe}$ and $\mathrm{Al} \mathrm{wt \%}$ in the mesoporous carbon composite is 
given in supplementary material page $\mathrm{S} 9, \mathrm{~S} 10$. The HR-TEM micrograph illustrates that formed $\gamma-\mathrm{Fe}_{2} \mathrm{O}_{3}$ and $\mathrm{FeAl}_{2} \mathrm{O}_{4}$ nanoparticles are uniformly distributed inside the mesopores of carbon matrix (Fig. $1 \mathrm{~b}(\mathrm{i})$ ). Furthermore, rings of bright spots in the SAED pattern are attributed to the diffraction pattern of uniformly distributed $\mathrm{\gamma}-\mathrm{Fe}_{2} \mathrm{O}_{3}$ and $\mathrm{FeAl}_{2} \mathrm{O}_{4}$ nanoparticles (Fig. $\mathrm{lb}$ (ii)). High magnified HR-TEM image shown in Fig. $1 \mathrm{~b}$ (iii),(iv) detect the fringes in $\gamma-\mathrm{Fe}_{2} \mathrm{O}_{3}$ and $\mathrm{FeAl}_{2} \mathrm{O}_{4}$ nanoparticles corresponding to interatomic distances between (311) and (220) planes of these phases, located adjacent to each other, with the $\mathrm{d}$ space values of 0.25 and $0.28 \mathrm{~nm}$, respectively. ${ }^{43,50}$ Although graphite diffraction peaks were not found in the wide-angle XRD pattern (Fig. S3), graphitization by partial reduction of $\mathrm{Fe}_{3} \mathrm{O}_{4}$ nanoparticles is confirmed through observed graphene layer with the $d$ value of $0.345 \mathrm{~nm}$ in Fig. $1 \mathrm{~b}$ (iv). ${ }^{51}$

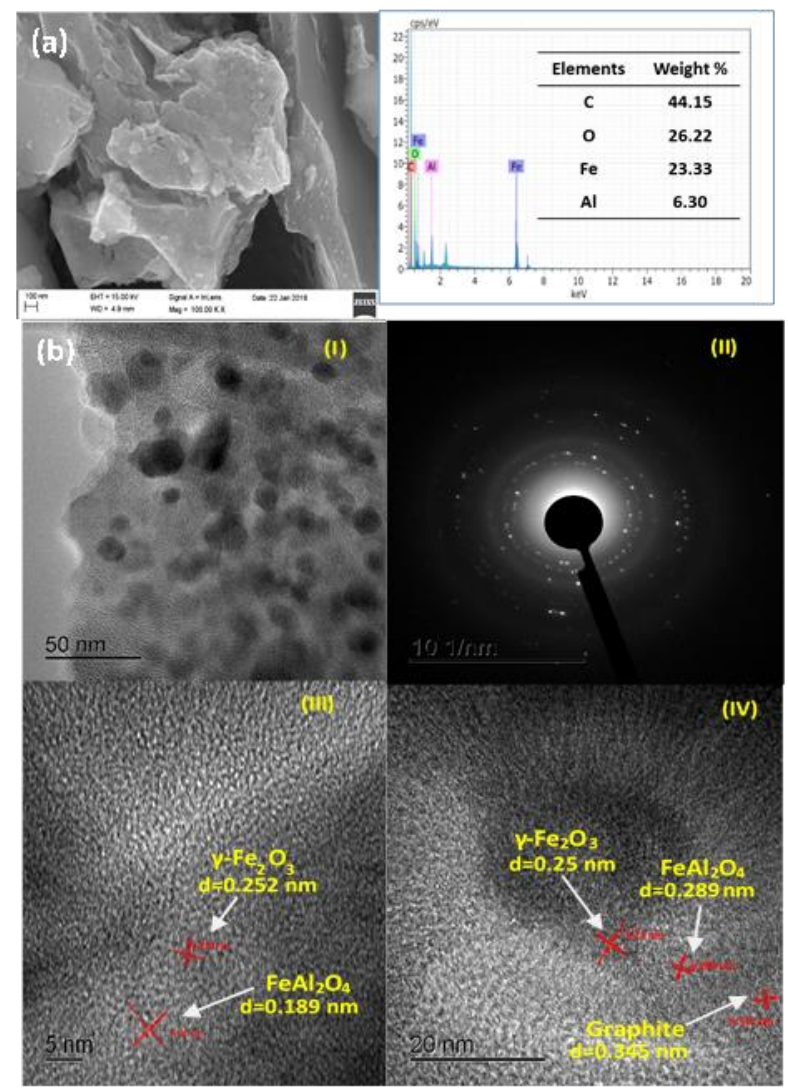

Fig. 1 (a) FE-SEM image with EDX and (b) HR-TEM images ((i), (iii),(iv)) and SAED pattern ((ii)) of $\gamma$ $\mathrm{Fe}_{2} \mathrm{O}_{3} / \mathrm{FeAl}_{2} \mathrm{O}_{4} @ \mathrm{MC}$

STEM image and STEM-EDX elemental maps shown in Fig. 2 have exposed the inner arrangement of $\gamma$ $\mathrm{Fe}_{2} \mathrm{O}_{3}$ and $\mathrm{FeAl}_{2} \mathrm{O}_{4}$ nanoparticles and comprehensive elemental distribution inside the carbon matrix of $y-\mathrm{Fe}_{2} \mathrm{O}_{3} / \mathrm{FeAl}_{2} \mathrm{O}_{4} @ \mathrm{MC}$. Unlike other elements such as $\mathrm{Al}, \mathrm{O}$ and $\mathrm{C}, \mathrm{Fe}$ has been distributed in the carbon matrix as discrete and aggregate forms. Furthermore, it is evident from the STEM image (Fig. 2) that a particle ejected out from carbon matrix (marked in the blue box) does not contain $\mathrm{C}$ and $\mathrm{Al}$, however, includes $\mathrm{Fe}$ and $\mathrm{O}$ elements. Thus, it is concluded that the aggregated form of Fe element represents iron oxide particles $\gamma-\mathrm{Fe}_{2} \mathrm{O}_{3}$ while the discrete form of Fe element - small particles of $\mathrm{FeAl}_{2} \mathrm{O}_{4}$ phase. Delightfully, STEM images further confirm that Al entered into the carbon matrix only through mesopores and reside adjacent to $y-\mathrm{Fe}_{2} \mathrm{O}_{3}$ as $\mathrm{FeAl}_{2} \mathrm{O}_{4}$ nanoparticles. All the above characterization results conclusively demonstrated that the fabricated $\gamma-\mathrm{Fe}_{2} \mathrm{O}_{3} / \mathrm{FeAl} \mathrm{O}_{2} @ M C$ possesses dispersed $\gamma$ $\mathrm{Fe}_{2} \mathrm{O}_{3}$ and $\mathrm{FeAl}_{2} \mathrm{O}_{4}$ nanoparticles located adjacent to each other inside the mesoporous carbon matrix. 


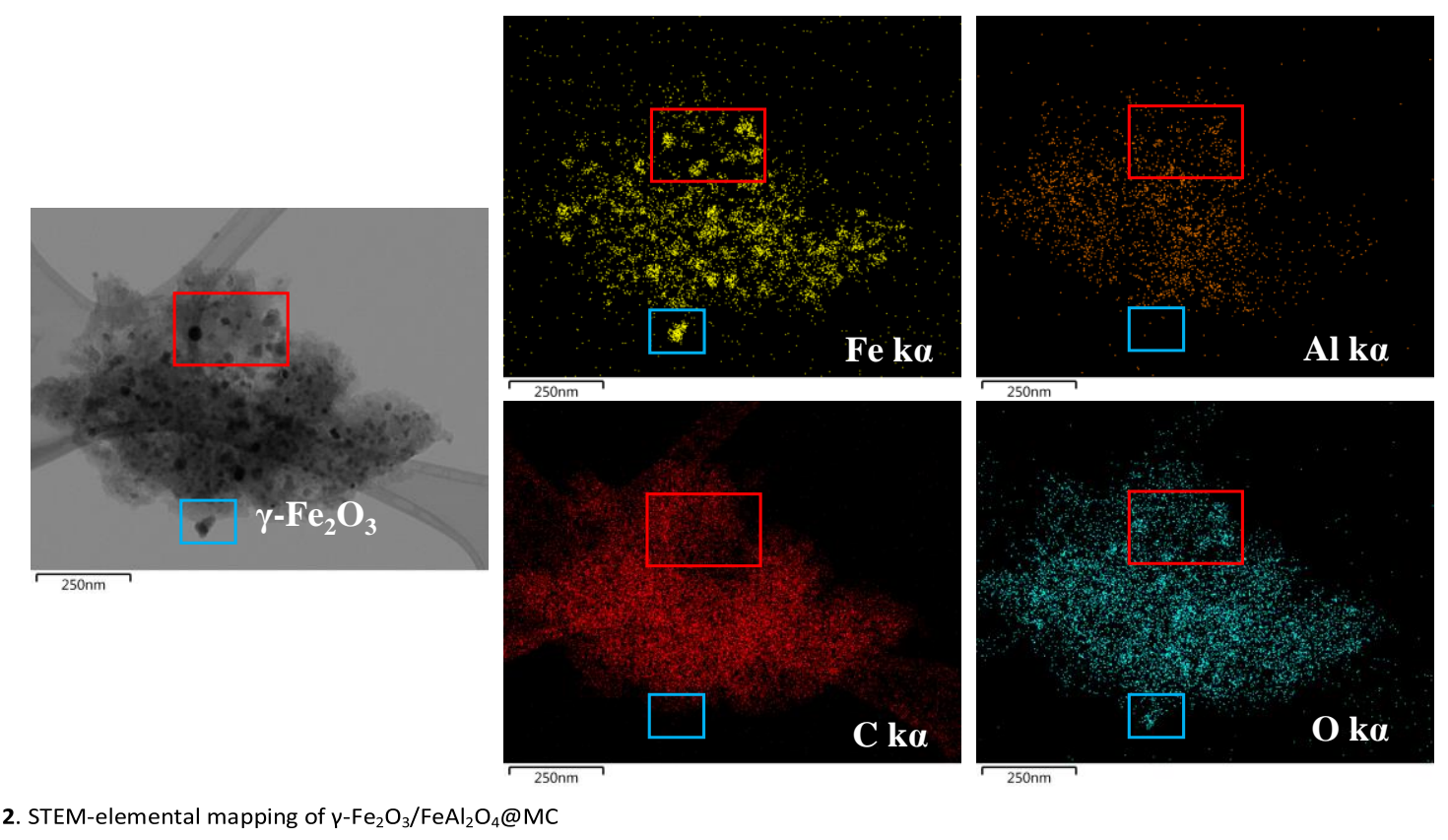

Catalytic performance of $\gamma-\mathrm{Fe}_{2} \mathrm{O}_{3} / \mathrm{FeAl}_{2} \mathrm{O}_{4} @ \mathrm{MC}$ in continuous up-flow fixed bed reactor towards $\mathrm{CWPO}$ of phenol

Effects of the $\mathrm{H}_{2} \mathrm{O}_{2}$ Concentration, Reaction Temperature, Initial pH and Feed Flow rate: Initially, influence of $\mathrm{H}_{2} \mathrm{O}_{2}$ concentration on the CWPO efficiency with $\boldsymbol{\gamma}-\mathrm{Fe}_{2} \mathrm{O}_{3} / \mathrm{FeAl}_{2} \mathrm{O}_{4} @ \mathrm{MC}$ catalyst was investigated at three different $\mathrm{H}_{2} \mathrm{O}_{2}$ concentration levels such as $\mathrm{S}, 1.2 \mathrm{~S}$ and 1.5S (S=Stoichiometric; 14 mol $\mathrm{H}_{2} \mathrm{O}_{2}: 1 \mathrm{~mol}$ phenol). The results displayed in Fig. 3a show that catalyst performed remarkably at all the three $\mathrm{H}_{2} \mathrm{O}_{2}$ concentration levels investigated at TOS (Time on Stream) up to $120 \mathrm{~h}$ of reaction. TOC removal increased from $\sim 68 \%$ to $\sim 75 \%$ with the increase in $\mathrm{H}_{2} \mathrm{O}_{2}$ concentration from $\mathrm{S}$ to $1.2 \mathrm{~S}$. Further increment of $\mathrm{H}_{2} \mathrm{O}_{2}$ amount (1.5S), does not have a significant impact on the complete phenol degradation represented by \%TOC removal owing to the scavenging of active $\mathrm{HO}$ by the excess $\mathrm{H}_{2} \mathrm{O}_{2}$ in the solution $\left(\mathrm{HO}^{\circ}+\mathrm{H}_{2} \mathrm{O}_{2} \rightarrow \mathrm{HOO}^{\circ}+\mathrm{H}_{2} \mathrm{O}\right) .{ }^{4}$ Based on the high TOC removal, $1.2 \mathrm{~S} \mathrm{H}_{2} \mathrm{O}_{2}$ was chosen as optimum concentration for further optimization studies. The impact of reaction temperature on the Fenton reaction was studied at 30,40 and $60{ }^{\circ} \mathrm{C}$ and the results are shown in Fig. $3 \mathrm{~b}$. The catalyst demonstrated poor performance at $30{ }^{\circ} \mathrm{C}$ as the TOC conversion was below $50 \%$ within $45 \mathrm{~h}$. Nevertheless, a mere $10{ }^{\circ} \mathrm{C}$ increase in temperature substantially improved the TOC removal to 75\% for $120 \mathrm{~h}$. Further increase in temperature to $60^{\circ} \mathrm{C}$ does not improve the catalyst's performance. It is due to the presence of robust low molecular weight intermediates (challenge to decompose) like oxalic, maleic and formic acids which contribute to the remaining 20-25\% TOC as detected by UPLC analysis (Fig. S9). The leached iron concentration in the effluent water at $30{ }^{\circ} \mathrm{C}$ is negligible $(<0.5 \mathrm{ppm})$ being $\sim 2 \mathrm{ppm}$ at 40 and $60^{\circ} \mathrm{C}$ despite of acidic $\mathrm{pH}$ at the reactor inlet and outlet $(\sim 3)$. Thus it has been decided to execute further optimization studies at lower temperature $40{ }^{\circ} \mathrm{C}$ important for the practical efficiency and feasibility of operation. It is noteworthy that acidification of the industrial wastewater prior to CWPO is not desirable since it could significantly increase the operational cost. Therefore, it was decided to conduct the $\mathrm{pH}$ optimization studies at $\mathrm{pH}$ of 5,6 and 7 (Fig. 3c). The synthesised catalyst displayed excellent activity at wide-range of $\mathrm{pH}$ from 3 to 7 . The average TOC removal of $76 \%$, $70 \%$ and $65 \%$ was observed at $\mathrm{pH} \mathrm{5,6}$ and 7, respectively, with less than $2 \mathrm{ppm}$ of iron leaching. This outcome certainly confirms that synthesised catalyst is capable to activate the $\mathrm{H}_{2} \mathrm{O}_{2}$ selectively (producing $\mathrm{HO}^{\circ}$ ) even at neutral $\mathrm{pH}$. It is clear that with respect to TOC conversion at the same other reaction conditions (temperature optimization study) $\mathrm{pH} 3$ and 5 demonstrated the identical catalytic activity. Since the natural pH of the $200 \mathrm{ppm}$ of phenol in water is ca 5 , this value has been chosen as optimum $\mathrm{pH}$. According to Fig. 3d the TOC removal decreases with increasing of feed flow rate from 0.1 to $0.3 \mathrm{~mL} / \mathrm{min}$. This means that at catalyst loading of $100 \mathrm{mg}$ the optimal residence time of pollutant phenol is achieved at solution flow rate not higher than $0.1 \mathrm{~mL} / \mathrm{min}$. 
Regardless of TOC conversion, the absence of phenol and other toxic intermediates in the effluent water needs to be confirmed. Thus, effluent water samples having TOC from 35 to $81 \%$ have been analysed using UPLC technique and the respective chromatograms are shown in Fig. S9. The UPLC chromatogram of the effluent water with $35 \%$ TOC removal displayed peaks corresponding to pollutant phenol and its partially oxidation intermediates such as fumaric, maleic and oxalic acid. On the other hand, the chromatogram of water sample having higher TOC conversion \% $(60,72$, and 81$)$ certainly confirm the absence of phenol and the presence of robust intermediate namely oxalic acid. From the above optimization study, it was concluded that favourable reaction conditions to accomplish the maximum degradation of $200 \mathrm{ppm}$ phenol through CWPO in fixed bed reactor are $1.2 \mathrm{~S} \mathrm{H}_{2} \mathrm{O}_{2}, \mathrm{~T}=40$ ${ }^{\circ} \mathrm{C}, \mathrm{pH}=5$ and $0.1 \mathrm{~mL} / \mathrm{min}$ flow rate of polluted water.
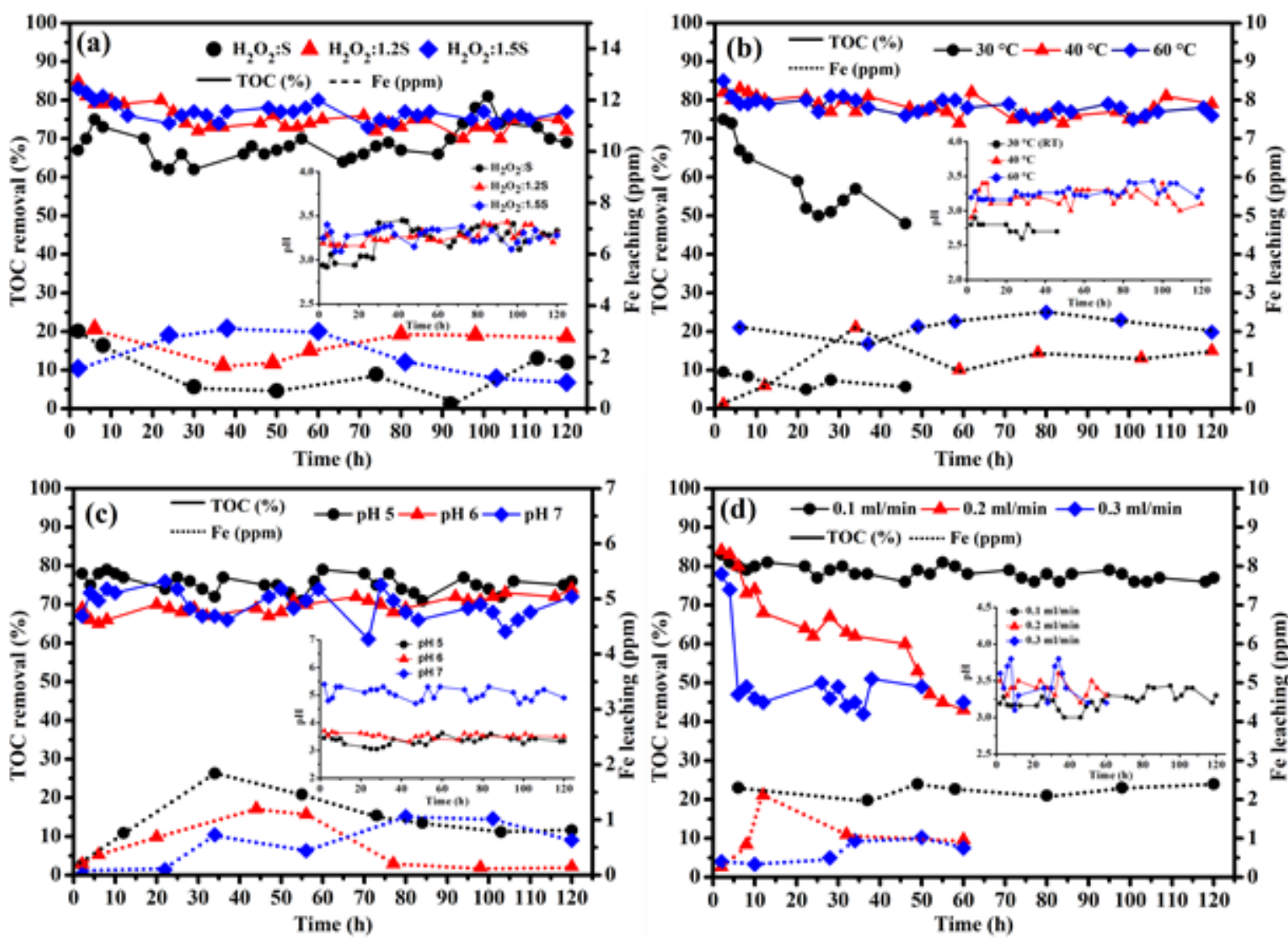

Fig. 3 Optimization of reaction parameters towards $200 \mathrm{ppm}$ phenol degradation over $100 \mathrm{mg} v-\mathrm{Fe}_{2} \mathrm{O}_{3} / \mathrm{FeAl}_{2} \mathrm{O}_{4} @ \mathrm{MC}$ in continuous up flow fixed bed

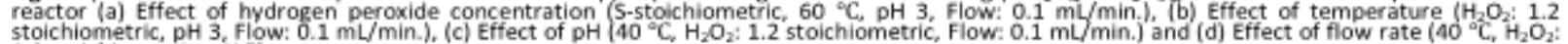
stoichiometric, $\mathrm{pH}$, Flow:
1.2 stoichiometric, $\mathrm{pH}$ )

The spent catalyst $\boldsymbol{\gamma}-\mathrm{Fe}_{2} \mathrm{O}_{3} / \mathrm{FeAl}_{2} \mathrm{O}_{4} @ M C$ that displayed the best performance at the optimized conditions was subjected to XRD analysis and the result is given in Fig. 4e. Unexpectedly, wide-angle XRD pattern does not contain peaks of $\gamma-\mathrm{Fe}_{2} \mathrm{O}_{3}$ and/or $\mathrm{FeAl}_{2} \mathrm{O}_{4}$. Instead of these phases, were detected peaks corresponding to $\mathrm{Fe}\left(\mathrm{Fe}_{0.66} \mathrm{Al}_{0.34}\right)_{2} \mathrm{O}_{4}$-aluminium substituted magnetite spinel with average crystal size of $35 \mathrm{~nm}$. Further, to detect the point of time of $\mathrm{Fe}\left(\mathrm{Fe}_{0.66} \mathrm{Al}_{0.34}\right)_{2} \mathrm{O}_{4}$ formation, four different batches of $\gamma$ - $\mathrm{Fe}_{2} \mathrm{O}_{3} / \mathrm{FeAl}_{2} \mathrm{O}_{4} @ M C$ catalyst were tested for the degradation study at TOS $=10,70,120$ and $250 \mathrm{~h}$ at the optimized conditions. In all four testing experiments the same catalytic activity towards phenol degradation corresponding to ca 78\% TOC removal (not shown) was measured. The X-ray diffractograms of spent catalyst discharged from the reactor after different TOS are shown in Fig. 5. For all the spent catalysts in this study the diffractograms exhibited peaks corresponding to $\mathrm{Fe}\left(\mathrm{Fe}_{0.68} \mathrm{Al}_{0.32}\right)_{2} \mathrm{O}_{4}$ with crystal size of ca $30 \mathrm{~nm}$. At the same time, it is important to evaluate the contribution of $\mathrm{MC}$ in the $\mathrm{Fe}\left(\mathrm{Fe}_{0.66} \mathrm{Al}_{0.34}\right)_{2} \mathrm{O}_{4} @ \mathrm{MC}$ catalyst towards the phenol degradation. HR-TEM 
images of graphitic MC shown in Fig. S10 display the cavities generated in the carbon matrix after the extraction of iron oxide particles and EDAX data acknowledges the XRD result (Fig. 4d) by showing only $0.10 \mathrm{wt} \% \mathrm{Fe}$ in the MC (Fig. S10). The graphitic MC demonstrated good TOC removal due to contribution of phenol adsorption at the beginning of run. However, as the time progresses TOC removal decreased to ca $50 \%$ (Fig. S11) corresponding to catalytic activity of graphite. On the other hand, hercynite- $\mathrm{FeAl}_{2} \mathrm{O}_{4}$ demonstrated better catalytic performance with TOC conversion of ca $65 \%$ (Fig. S11). However, wide-angle XRD analysis of fresh and spent $\mathrm{FeAl}_{2} \mathrm{O}_{4}$ confirmed that during the reaction time of $120 \mathrm{~h}$ half of the catalyst decomposed (Fig. $4 \mathrm{~b}, \mathrm{c}$ ). Therefore, the observed high catalytic activity of $\mathrm{FeAl}_{2} \mathrm{O}_{4}$ might be caused by contribution $\mathrm{Fe}^{2+}$ ions released from it and catalyzing phenol degradation homogeneously. Undoubtedly the results of above set of experiment's corroborates that the observed high catalytic activity of $\boldsymbol{\nu}-\mathrm{Fe}_{2} \mathrm{O}_{3} / \mathrm{FeAl}_{2} \mathrm{O}_{4} @ \mathrm{MC}$ catalyst has solely arisen from the $\mathrm{Fe}\left(\mathrm{Fe}_{0.68} \mathrm{Al}_{0.32}\right)_{2} \mathrm{O}_{4}$ aluminium substituted magnetite spinel nanoparticles encapsulated in $\mathrm{MC}$ that were formed in situ at the reaction conditions of phenol CWPO at starting period of $<10 \mathrm{~h}$.

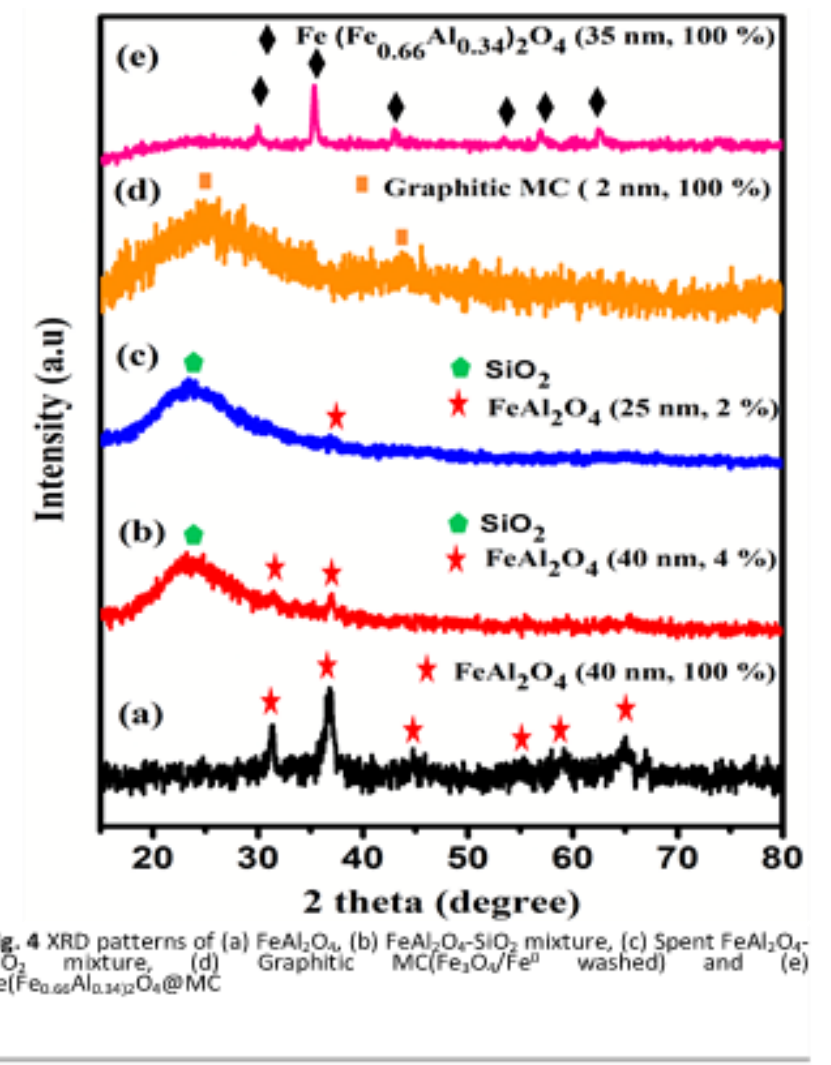

Catalytic activity and stability of Al doped magnetite- $\mathrm{Fe}\left(\mathrm{Fe}_{0.68} \mathrm{Al}_{0.32}\right)_{2} \mathrm{O}_{4}$

To evaluate the activity and stability of the $\mathrm{Fe}\left(\mathrm{Fe}_{0.68} \mathrm{Al}_{0.32}\right)_{2} \mathrm{O}_{4} @ \mathrm{MC}$ catalyst it was conducted the long term time on stream study and periodical analysis of the discharged water to estimate the presence Fe and Al. The catalyst exhibited remarkable performance towards phenol degradation of ca $80 \%$ TOC conversion for $500 \mathrm{~h}$ with maximum $2 \mathrm{ppm}$ of Fe leaching (Fig. 6). Alike Fe, maximum 3ppm of Al was found in the effluent water throughout $500 \mathrm{~h}$ of reaction. Since the catalyst continued its high performance up to $500 \mathrm{~h}$ without visible deactivation, the test was stopped, reactor has been discharged and the spent catalyst was examined by XRD analysis. The wide-angle XRD pattern of 500 $\mathrm{h}$ spent catalyst shown in Fig .5e - endorses the formation of aluminium doped magnetite spinel $\mathrm{Fe}\left(\mathrm{Fe}_{0.68} \mathrm{Al}_{0.32}\right)_{2} \mathrm{O}_{4}$ structure of $35 \mathrm{~nm}$ crystal size inside $\mathrm{MC}$ (identical pattern of the previous spent catalysts) with the molar composition of $\mathrm{FeAl}_{0.27} \mathrm{O}_{1.7}$ and $\mathrm{Fe} / \mathrm{Al}$ mole ratio of 3.7. It was found that the concentration of Fe and $\mathrm{Al}$ in the effluent water collected after all test is 1 and $2 \mathrm{ppm}$, respectively. Therefore, the absolute concentration of $\mathrm{Fe}$ and $\mathrm{Al}$ in 3 litres of purified water collected in this run $(0.1 \mathrm{~mL} / \mathrm{min}$ for $500 \mathrm{~h})$ would be $3 \mathrm{and} 6 \mathrm{mg}$, respectively. The result of ICP-OES analysis of $500 \mathrm{~h}$ spent catalyst shown in Table 1 confirms the presence of $19.85 \mathrm{mg}$ Fe and $2.52 \mathrm{mg} \mathrm{Al}$ in 100mg of the fresh 
catalyst loaded to reactor with $\mathrm{Fe} / \mathrm{Al}$ atomic ratio of 3.8 (Detailed calculations are given in the supplementary material at page S9, S10). Remarkably, Fe/Al mole ratio (3.7) in the $500 \mathrm{~h}$ spent catalyst corresponds to composition of substituted spinel phase detected for this catalyst by XRD being in good agreement with the Fe/Al mole ratio (3.8) obtained from ICP-OES analysis result of $500 \mathrm{~h}$ spent catalyst. The consistent performance of the catalyst up to $500 \mathrm{~h}$ validates the absence of catalyst loss from the reactor. The estimated pressure drop was less than 0.1 bar across the catalyst bed. In order to verify the contribution of leached iron to the phenol degradation, a study was performed in the empty fixed

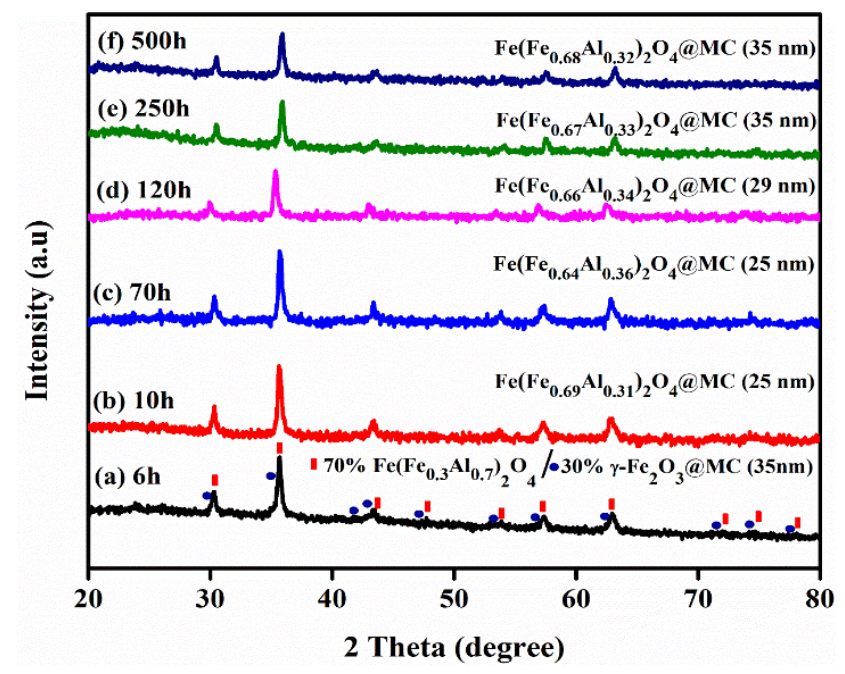

Fig. 5 XRD patterns of $\mathrm{Y}-\mathrm{Fe}_{2} \mathrm{O}_{3} / \mathrm{FeAl}_{2} \mathrm{O}_{4} @ \mathrm{MC}$ spent catalyst (a) $6 \mathrm{~h}$ (b) $10 \mathrm{~h}$, (c) $70 \mathrm{~h}$, (d) $120 \mathrm{~h}$, (e) $250 \mathrm{~h}$ and (f) $500 \mathrm{~h}$ (Reaction conditions: $200 \mathrm{ppm}$ phenol, $\mathrm{pH}=5, \mathrm{~T}=40^{\circ} \mathrm{C}, \mathrm{H}_{2} \mathrm{O}_{2}: 1.2 \mathrm{~S}$, Flow rate: $0.1 \mathrm{~mL} / \mathrm{min}$ ).

bed reactor at the optimized conditions with $2 \mathrm{ppm}$ of dissolved iron corresponding to the limit for water discharge into the environment (Figure S12). It was found that $2 \mathrm{ppm}$ of homogeneous iron exhibited about $50 \%$ TOC removal at the optimized conditions which is significantly less compared to the $80 \%$ TOC conversion achieved with the $\mathrm{Fe}\left(\mathrm{Fe}_{0.68} \mathrm{Al}_{0.32}\right)_{2} \mathrm{O}_{4} @ \mathrm{MC}$ catalyst. Since in the testing of $\mathrm{Fe}\left(\mathrm{Fe}_{0.68} \mathrm{Al}_{0.32}\right)_{2} \mathrm{O}_{4} @ \mathrm{MC}$ heterogeneous catalyst in a long $500 \mathrm{~h}$ run the content of leached iron during the last $325 \mathrm{~h}$ was $<1 \mathrm{ppm}$ (Fig6), it may be concluded that the contribution of homogeneous catalysis by leached iron to the total TOC removal is negligible.

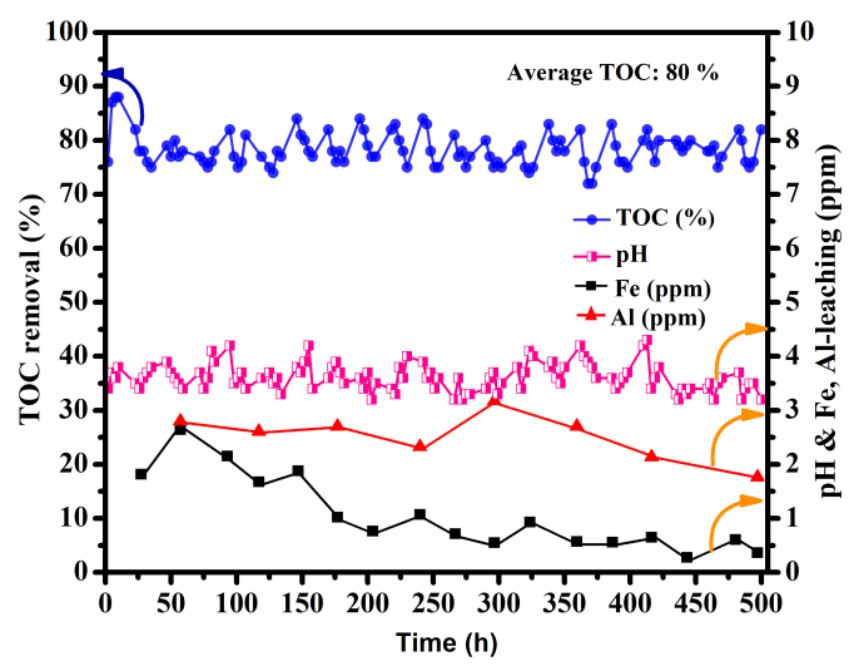

Fig. 6 Time on stream study of in-situ formed Fe( $\left.\mathrm{Fe}_{0.68} \mathrm{Al}_{0_{0.32}}\right)_{2} \mathrm{O}_{4} @ \mathrm{MC}$ towards phenol degradation in fixed-bed reactor (Reaction conditions: $200 \mathrm{ppm}$ phenol, $\mathrm{pH}=5, \mathrm{~T}=40^{\circ} \mathrm{C}, \mathrm{H}_{2} \mathrm{O}_{2}: 1.2 \mathrm{~S}$, Flow rate: $0.1 \mathrm{~mL} / \mathrm{min}$ ). 
In the interest of disclosing the influence of $\mathrm{Al}$ in magnetite nanoparticles $\left(\mathrm{Fe}\left(\mathrm{Fe}_{0.68} \mathrm{Al}_{0.32}\right)_{2} \mathrm{O}_{4}\right)$ to enhance the redox cycle and stability, synthesised $\left(\mathrm{Fe}_{3} \mathrm{O}_{4} / \mathrm{Fe}^{0} @ M C\right.$ and $\left.\boldsymbol{\nu}-\mathrm{Fe}_{2} \mathrm{O}_{3} / \mathrm{FeAl}_{2} \mathrm{O}_{4} @ M C\right)$ and the spent composite catalyst after $500 \mathrm{~h}$ run $\left(\mathrm{Fe}\left(\mathrm{Fe}_{0.68} \mathrm{Al}_{0.32}\right)_{2} \mathrm{O}_{4} @ \mathrm{MC}\right)$ were further investigated using XPS technique to gain insight into the electrons binding energy and oxidation state of $\mathrm{Fe}$ and $\mathrm{Al}$ (Fig. 7,S13). The XPS spectra of $\mathrm{Fe}_{3} \mathrm{O}_{4} / \mathrm{Fe}^{0} @ \mathrm{MC}$ composite display three peaks of Fe2p core at binding energy values of $702,711.1$ and $724.7 \mathrm{eV}$ (Fig. 7a). The small peak at $702 \mathrm{eV}$ is assigned to metallic iron $\left(\mathrm{Fe}^{0}\right)^{52}$ and remaining two distinct broad peaks with the binding energy of $711.1 \mathrm{eV}$ and $724.7 \mathrm{eV}$ are assigned to $\mathrm{Fe} 2 \mathrm{p}_{3 / 2}$ and Fe2 $\mathrm{p}_{1 / 2}$ respectively. Broader Fe2 $\mathrm{p}_{3 / 2}$ peak was fitted with a major peak at $711.2 \mathrm{eV}$ and the minor one at $710 \mathrm{eV}$ corresponding to $\mathrm{Fe}^{2+}$ and $\mathrm{Fe}^{3+}$ of $\mathrm{Fe}_{3} \mathrm{O}_{4}$, respectively (Fig. $\left.7 \mathrm{~b}\right)^{53}$. On the other hand, metallic iron ( $\left.\mathrm{Fe}^{0}\right)$ peak at $702 \mathrm{eV}$ is absent in $\gamma-\mathrm{Fe}_{2} \mathrm{O}_{3} / \mathrm{FeAl}_{2} \mathrm{O}_{4} @ \mathrm{MC}$ (Fig. 7a) which compliments the XRD inference. Alike $\mathrm{Fe}_{3} \mathrm{O}_{4}, \mathrm{Y}-\mathrm{Fe}_{2} \mathrm{O}_{3}$ also display one intense peak at $711.4 \mathrm{eV}\left(\mathrm{Fe} 2 \mathrm{p}_{3 / 2}\right)$ and a weak peak at $725\left(\mathrm{Fe} 2 \mathrm{p}_{1 / 2}\right)$ besides a small shakeup satellite peak at $719.2 \mathrm{eV}$. It is attributed to the fingerprint of the electronic structure of $\gamma-\mathrm{Fe}_{2} \mathrm{O}_{3}$ whereas, in the case of $\mathrm{Fe}_{3} \mathrm{O}_{4}$ shakeup satellite peak does not appear $^{54}$. On deconvolution, broad $\mathrm{Fe}_{2} \mathrm{p}_{3 / 2}$ peak resolved into two peaks at binding energy $710.3 \mathrm{eV}$ assigned to $\mathrm{Fe}^{2+}$ in $\mathrm{FeAl}_{2} \mathrm{O}_{4}{ }^{55}$ and $712.5 \mathrm{eV}$ ascribed to $\mathrm{Fe}^{3+}$ in $\gamma-\mathrm{Fe}_{2} \mathrm{O}_{3}$ (Fig. 7c) ${ }^{56}$. Deconvoluted spectra of Al2p core exhibit peaks at binding energies 74.5 and $75.1 \mathrm{eV}$ correspond to the $\mathrm{Al}^{3+}$ in the hercynite nanoparticle as reported in the literature (Fig. $7 d)^{55}$. Broader $\mathrm{Fe} 2 \mathrm{p}_{3 / 2}$ peak of spent catalyst$\mathrm{Fe}\left(\mathrm{Fe}_{0.63} \mathrm{Al}_{0.32}\right)_{2} \mathrm{O}_{4}$ shown in Fig. 7e is fitted with a peak at $710.4 \mathrm{eV}$ and $712.3 \mathrm{eV}$ corresponding to $\mathrm{Fe}^{2+}$ and $\mathrm{Fe}^{3+}$, respectively. The deconvoluted Al2p spectra exhibit peaks at binding energies of 74.5 and $74.1 \mathrm{eV}$ corresponding, respectively, to the $\mathrm{Al}$ ions in Al-O-Al and Al-O-Fe linkages that exist in the $\mathrm{Fe}\left(\mathrm{Fe}_{0.68} \mathrm{Al}_{0.32}\right)_{2} \mathrm{O}_{4}$ structure (Fig. 7f). XPS results certainly confirm the existence of $\mathrm{Fe}^{2+}$ and $\mathrm{Fe}^{3+}$ in the structure of $\mathrm{Fe}\left(\mathrm{Fe}_{0.68} \mathrm{Al}_{0.32}\right)_{2} \mathrm{O}_{4}$ spinel nanoparticles. Furthermore, it isimportant to note that on formation of Al-substituted magnetite, binding energy values of both $\mathrm{Fe}^{2+}$ and $\mathrm{Fe}^{3+}$ have been increased from 710 and $711.2 \mathrm{eV}\left(\mathrm{Fe}_{3} \mathrm{O}_{4} / \mathrm{Fe}^{0} @ \mathrm{MC}\right.$, Fig. $\left.7 \mathrm{~b}\right)$ to $710.4 \mathrm{eV}$ and $712.3 \mathrm{eV}$, respectively $\left(\mathrm{Fe}\left(\mathrm{Fe}_{0.68} \mathrm{Al}_{0.32}\right)_{2} \mathrm{O}_{4} @ M C\right.$, Fig. 7e). The XPS spectra of $\mathrm{C} 1 \mathrm{~s}$ core of $500 \mathrm{~h}$ spent $\mathrm{Fe}\left(\mathrm{Fe}_{0.68} \mathrm{Al}_{0.32}\right)_{2} \mathrm{O}_{4} @ \mathrm{MC}$ catalyst is shown Fig. S14. After deconvolution of the spectra, catalyst exhibited two peaks at binding energy values of $284.1 \mathrm{eV}$ and $285.1 \mathrm{eV}$ corresponds to $\mathrm{sp}^{2}(\mathrm{C}=\mathrm{C})$ and $\mathrm{sp}^{3}(\mathrm{C}-\mathrm{C})$ hybridized carbon ${ }^{57}$. The absence of peaks at $287.2 \mathrm{eV}, 285.8 \mathrm{eV}$ and $288.6 \mathrm{eV}$ corresponding to $\mathrm{C}=\mathrm{O}, \mathrm{C}-\mathrm{O}, \mathrm{O}-\mathrm{C}-\mathrm{O}$ functional groups corroborates the nonfunctionalized nature of carbon matrix after $500 \mathrm{~h}$ long run and is evident for the high stability of the carbon shell against oxidative decomposition at phenol degradation conditions. Hence, based on the XPS results and earlier observation of decomposition of hercynite nanoparticles at the working conditions of CWPO in the reactor, we envisaged the following occurrences which ultimately created $\mathrm{Fe}\left(\mathrm{Fe}_{0.68} \mathrm{Al}_{0.32}\right)_{2} \mathrm{O}_{4}$ spinel nanoparticle inside $\mathrm{MC}$.
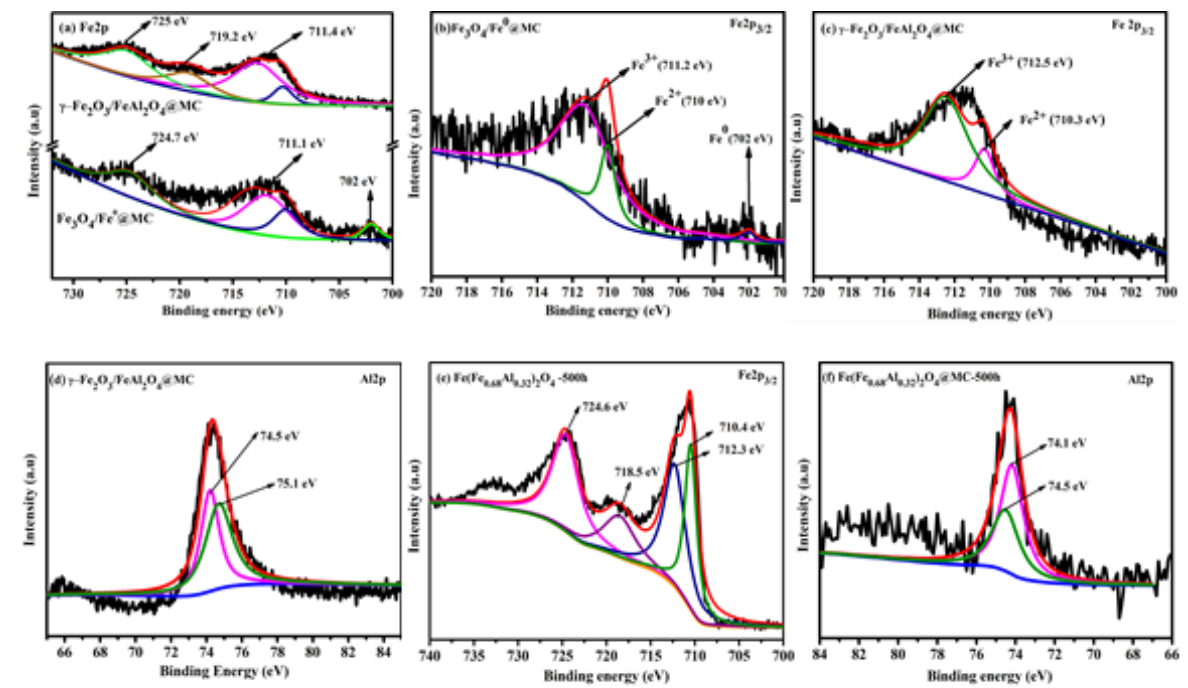

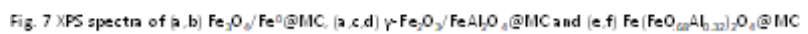


It is well known that maghemite- $\boldsymbol{\gamma}-\mathrm{Fe}_{2} \mathrm{O}_{3}$ derived from magnetite- $\mathrm{Fe}_{3} \mathrm{O}_{4}$ contains cation vacancies in its structure. Both magnetite and maghemite exhibit spinel crystal structure however, the former holds $\mathrm{Fe}^{2+}$ and $\mathrm{Fe}^{3+}$ cations together at the octahedral site while the latter contains only $\mathrm{Fe}^{3+}$. The cation vacancy $(\square)$ present in the maghemite ensures the charge neutrality and its unit cell is denoted as $\left(\mathrm{Fe}^{3+}\right)_{8}\left[\mathrm{Fe}^{3+}{ }_{5 / 6} \square_{1 / 6}\right]_{16} \mathrm{O}_{32}$ where ( $)$ and [ ] represents tetrahedral and octahedral site respectively ${ }^{58}$. As the $\gamma-\mathrm{Fe}_{2} \mathrm{O}_{3} / \mathrm{FeAl}_{2} \mathrm{O}_{4} @ M C$ is acquired from $\mathrm{Fe}_{3} \mathrm{O}_{4} / \mathrm{Fe}^{0} @ M C$, certainly cation vacancy would be present in the $\boldsymbol{\gamma}-\mathrm{Fe}_{2} \mathrm{O}_{3}$ structure. At the working conditions of CWPO, as observed earlier, $\mathrm{FeAl}_{2} \mathrm{O}_{4}$ in the solid solution of $\boldsymbol{\nu}-\mathrm{Fe}_{2} \mathrm{O}_{3} / \mathrm{FeAl}_{2} \mathrm{O}_{4} @ M C$ decomposes and part of the released $\mathrm{Al}^{3+}$ ions occupies cation vacancies at octahedral sites of $\boldsymbol{\gamma}-\mathrm{Fe}_{2} \mathrm{O}_{3}$. Subsequently, $\mathrm{Fe}^{3+}$ at the octahedral and tetrahedral site gets reduced to $\mathrm{Fe}^{2+}$ by reacting with $\mathrm{H}_{2} \mathrm{O}_{2}$ to maintain the charge neutrality. Thus the biphase $\boldsymbol{\gamma}-\mathrm{Fe}_{2} \mathrm{O}_{3} / \mathrm{FeAl}_{2} \mathrm{O}_{4}$ composition is converted to a one phase $\mathrm{Al}$ substituted magnetite spinel structure with the general formula of $\mathrm{Fe}^{3+}{ }_{1-x} \mathrm{Fe}^{2+}{ }_{x}\left[\left(\mathrm{Fe}^{2+} \mathrm{Fe}^{3+}\right)_{0.5(1-x)} \mathrm{Al}^{3+}{ }_{x}\right]_{2} \mathrm{O}_{4} @ M C$ where $\mathrm{x}$ represents the amount of $\mathrm{Al}$ in composition. The $\mathrm{Fe}^{2+}$ and remaining $\mathrm{Al}^{3+}$ discharged from $\mathrm{FeAl}_{2} \mathrm{O}_{4}$ are captured in the catalyst bed and released slowly along with the effluent water (Fig. 6) ${ }^{25}$. It is noteworthy that the observed high catalytic activity is exclusively emerged from the solid $\mathrm{Fe}^{3+}{ }_{1-x} \mathrm{Fe}^{2+}{ }_{x}\left[\left(\mathrm{Fe}^{2+} \mathrm{Fe}^{3+}\right)_{0.5(1-x)} \mathrm{Al}^{3+}{ }_{x}\right]_{2} \mathrm{O}_{4} @ \mathrm{MC}$ spinel nanoparticles as the homogeneous $\mathrm{Fe}^{2+}$ ions concentration is about $1 \mathrm{ppm}$ throughout $500 \mathrm{~h}$ of the reaction run (Fig. 6) with insignificant contribution to phenol degradation. It was observed through a separate study that hydrogen peroxide at $30^{\circ} \mathrm{C}$ decomposes the hercynite- $-\mathrm{FeAl}_{2} \mathrm{O}_{4}$ at a very slow rate. Thus, formation of Al-doped magnetite inside the mesoporous carbon is severely affected consequently, and catalyst obtained from $\mathrm{\gamma}-\mathrm{Fe}_{2} \mathrm{O}_{3} / \mathrm{FeAl}_{2} \mathrm{O}_{4}$ solid solution demonstrated poor catalytic activity at $30^{\circ} \mathrm{C}$ (Fig. 3b).

After 10 hours of run at $\mathrm{T}=40^{\circ} \mathrm{C}$ the catalysts composition is already represented by Al-substituted magnetite spinel with $x=0.31$ (Fig. 5a) resulted in formula $\mathrm{Fe}^{3+}{ }_{0.69} \mathrm{Fe}^{2+}{ }_{0.31}\left(\mathrm{Fe}^{2+}{ }_{0.34} \mathrm{Fe}^{3+}{ }_{0.34} \mathrm{Al}^{3+}{ }_{0.31}\right)_{2} \mathrm{O}_{4}$. Notably, $\mathrm{Fe}^{2+} / \mathrm{Fe}^{3+}$ ion pairs exist equally at the octahedral sites and this coordination is being maintained regardless of Al content. As the octahedral sites are almost exclusively exposed at the surface of the magnetite spinel structure, the observed catalytic activity is related to the $\mathrm{Fe}^{2+} / \mathrm{Fe}^{3+}$ ion pairs at this coordination ${ }^{59}$. XPS results certainly confirm the influence of $\mathrm{Al}$ on iron ions in the magnetite structure through a substantial shift to higher binding energy of $1.1 \mathrm{eV}$ for Fe ${ }^{3+}$ and minor shift of $0.4 \mathrm{eV}$ for $\mathrm{Fe}^{2+}$ compared to Al free magnetite (Fig. 7b, 7e). It can be ascribed to the polarization of electrons around iron ions by attracting of electron density from iron centre by $\mathrm{Al}^{3+}$ through its Lewis acid property that subsequently increases the electropositive nature on the iron ions $\left(\mathrm{Fe}^{\mathrm{n}+(\delta+)}\right)^{35}$. It is established that among the redox reactions of $\mathrm{Fe}^{2+}$ and $\mathrm{Fe}^{3+}$ with $\mathrm{H}_{2} \mathrm{O}_{2}$, the reduction reaction of $\mathrm{Fe}^{3+}$ to produce $\mathrm{HOO}^{\circ}$ is kinetically less favourable ${ }^{4}$. However, in our case, the additional electropositive character on $\mathrm{Fe}^{3+(\delta+)}$ could expedite the kinetically slow reduction reaction of $\mathrm{Fe}^{3+}$ to produce $\mathrm{HOO}$. Consequently, generated $\mathrm{HO}$ and $\mathrm{HOO}$ radicals oxidize the phenol effectively with $80 \%$ TOC removal at mild operating conditions $\left(\mathrm{pH} 5,40^{\circ} \mathrm{C}\right)$. A plausible mechanism, therefore, has been proposed by involving the $\mathrm{Fe}^{2+}$ and $\mathrm{Fe}^{3+}$ ions at the octahedral sites of the $\mathrm{Al}$ substituted magnetite spinel to produce desired $\mathrm{HO}^{\circ}$ and $\mathrm{HOO}^{\circ}$ radicals (Scheme 2). We envisage that the oxidation of $\mathrm{Fe}^{2+}$ and reduction of $\mathrm{Fe}^{3+}$ in the spinel takes place concurrently by reacting with $\mathrm{H}_{2} \mathrm{O}_{2}$. The reaction starts with kinetically favourable oxidation reaction of $\mathrm{Fe}^{2+}$ to $\mathrm{Fe}^{3+}$ to produce $\mathrm{HO}$ and establishes a charge imbalance in the spinel structure. In consequence, $\mathrm{Fe}^{3+}$ obtained by $\mathrm{Fe}^{2+}$ oxidation pulls the electron from the adjacent electropositive $\mathrm{Fe}^{3+(\delta+)}$ at the octahedral site to attain charge neutrality. Concurrently, $\mathrm{Fe}^{3+(\delta+)}$ abstracts an electron from $\mathrm{H}_{2} \mathrm{O}_{2}$ to produce $\mathrm{HOO}^{\circ}$ and oxidizes by reducing the adjacent $\mathrm{Fe}^{3+}$ to $\mathrm{Fe}^{2+}$ as shown in Scheme 2 . This redox cycle proceeds continuously to produce the required active $\mathrm{HO}^{\circ}$ and $\mathrm{HOO}^{\circ}$ radical species for phenol degradation. The influence of substituted Al by polarizing Fe electrons through its Lewis acid property imparts more positive charge on iron ions $\left(\mathrm{Fe}^{\mathrm{n}+(\delta+)}\right)$ in turn strengthening their binding in spinel structure. 


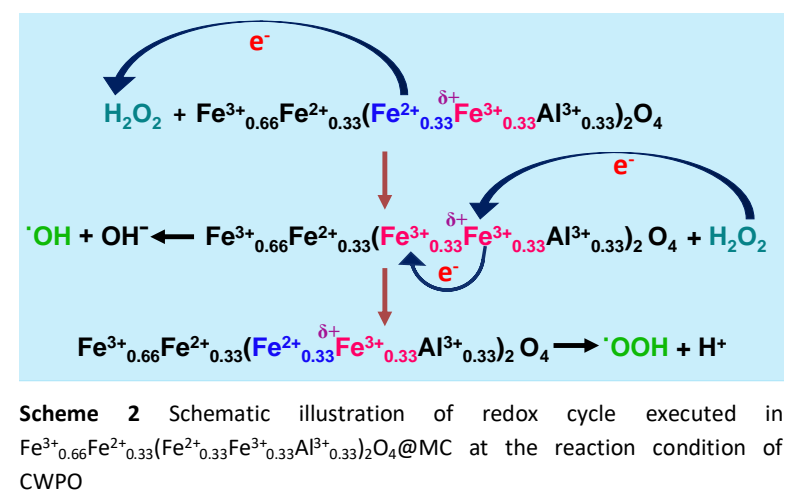

Consequently, high resistance of Fe-Al-O spinel to dissolution at experimented $\mathrm{pH}$ values together with encapsulation of Fe-Al-O spinel nanoparticles by carbon shells determined low leaching level of $\mathrm{Fe}$ and Al ions from Al-doped magnetite spinel and provided stability with high TOC conversion at least up to $500 \mathrm{~h}$ of reaction. Finally, the magnetic property of the obtained $\mathrm{Fe}\left(\mathrm{Fe}_{0.68} \mathrm{Al}_{0.32}\right)_{2} \mathrm{O}_{4} @ \mathrm{MC}$ material helps to separate the catalyst discharged after the reaction from the silica-gel diluent using the external magnet.

The kinetic data obtained for $\mathrm{Fe}\left(\mathrm{Fe}_{0.68} \mathrm{Al}_{0.32}\right)_{2} \mathrm{O}_{4} @ \mathrm{MC}$ at different space time $\tau=1 /$ LHSV (LHSV-liquid hourly space velocity) from oxidation tests were interpreted according to a simplified first order kinetic equation model which validity for CWPO of organic pollutants in a fixed-bed reactor was proven in ${ }^{60,61}$. The pseudo-first order rate constant $\left(\mathrm{k}\left(\mathrm{h}^{-1}\right)\right)$ of complete phenol mineralization to $\mathrm{CO}_{2}$ (TOC removal$\left.\mathrm{X}_{\mathrm{TOC}}\right)$ was calculated using the equation 3. It implies that $\mathrm{Fe}\left(\mathrm{Fe}_{0.68} \mathrm{Al}_{0.32}\right)_{2} \mathrm{O}_{4} @ \mathrm{MC}$ catalyst display the high rate constant value of $8.4 \mathrm{~h}^{-1}$ (Fig. S15). The catalytic performance of $\mathrm{Fe}\left(\mathrm{Fe}_{0.68} \mathrm{Al}_{0.32}\right)_{2} \mathrm{O}_{4} @ \mathrm{MC}$ towards phenol degradation is compared in Table S1. with the performance of other reported heterogeneous Fenton catalysts. The results suggest that $\mathrm{Fe}\left(\mathrm{Fe}_{0.68} \mathrm{Al}_{0.32}\right)_{2} \mathrm{O}_{4} @ \mathrm{MC}$ catalyst appears a better catalyst in respect of activity and stability. $80 \%$ TOC removal was achieved with $\mathrm{Fe}\left(\mathrm{Fe}_{0.68} \mathrm{Al}_{0.32}\right)_{2} \mathrm{O}_{4} @ M C$ catalyst at twice lower temperature and for period of time longer by a factor of 5-16 compared with reported catalytic materials.

$$
\left.\ln \left(1-X_{\text {TOC }}\right)=-k \cdot \tau \quad \text { (Eq. } 3\right)
$$

\section{Conclusions}

In this study, Al-doped magnetite was proved as an efficient heterogeneous Fenton catalyst toward degradation of robust pollutant phenol in continuous system for practical applications. Based on the results of characterization and control experiments it was concluded that in situ formed nanoparticles of Al-substituted magnetite spinel with formula $\mathrm{Fe}^{3+}{ }_{0.68} \mathrm{Fe}^{2+}{ }_{0.32}\left(\mathrm{Fe}^{2+}{ }_{0.34} \mathrm{Fe}^{3+}{ }_{0.34} \mathrm{Al}^{3+}{ }_{0.32}\right)_{2} \mathrm{O}_{4}$ encapsulated inside mesoporous carbon are responsible for the observed high catalytic activity. It appears that substituted $\mathrm{Al}$ ions in the $\mathrm{Fe}^{3+}{ }_{0.68} \mathrm{Fe}^{2+}{ }_{0.32}\left(\mathrm{Fe}^{2+}{ }_{0.34} \mathrm{Fe}^{3+}{ }_{0.34} \mathrm{Al}^{3+}{ }_{0.32}\right)_{2} \mathrm{O}_{4} @ \mathrm{MC}$ polarizes electrons around the iron atoms through their Lewis acid property and expedites the challenging reduction reaction of $\mathrm{Fe}^{3+}$ with $\mathrm{H}_{2} \mathrm{O}_{2}$ to produce $\mathrm{HOO}$. Consequently at the mild operating conditions $\left(\mathrm{pH} 5,40^{\circ} \mathrm{C}\right)$ $\mathrm{Fe}^{3+}{ }_{0.68} \mathrm{Fe}^{2+}{ }_{0.32}\left(\mathrm{Fe}^{2+}{ }_{0.34} \mathrm{Fe}^{3+}{ }_{0.34} \mathrm{Al}^{3+}{ }_{0.32}\right)_{2} \mathrm{O}_{4} @ \mathrm{MC}$ degraded the phenol in the fixed-bed reactor with 80\% TOC conversion and $\sim 1 \mathrm{ppm}$ concentration of leached Fe for $500 \mathrm{~h}$. The major shortcomings that exist thus far in the heterogeneous Fenton catalysis such as low stability and activity, inability to perform at mild condition like low temperature and wide range of $\mathrm{pH}$ is overcome in this study through the synthesised $\mathrm{Fe}^{3+}{ }_{0.68} \mathrm{Fe}^{2+}{ }_{0.32}\left(\mathrm{Fe}^{2+}{ }_{0.34} \mathrm{Fe}^{3+}{ }_{0.34} \mathrm{Al}^{3+}{ }_{0.32}\right)_{2} \mathrm{O}_{4} @ \mathrm{MC}$ catalyst. Heterogeneous Fenton catalysts have never been applied industrially for the treatment of wastewaters in continuous mode as there are not available yet catalysts with required characteristics of high activity, low cost, negligible leaching of catalysts components, and high stability. Thus, this work would pave the way to employ Al substituted magnetite spinel nanoparticles as a basis for development of heterogeneous Fenton catalyst answering the requirements of practical application for industrial wastewater treatment. 


\section{Conflicts of interest}

"There are no conflicts to declare".

\section{Acknowledgements}

This study was financially supported by VIT transdisciplinary grant from VIT management.

\section{Notes and references}

1 B. Guieysse and Z. N. Norvill, J. Hazard. Mater., 2014, 267, 142-152.

2 A. Giwa, A. Yusuf, H. A. Balogun, N. S. Sambudi, M. R. Bilad, I. Adeyemi, S. Chakraborty and S. Curcio, Process Saf. Environ. Prot., 2021, 146, 220-256.

3 P. Bautista, A. F. Mohedano, J. A. Casas, J. A. Zazo and J. J. Rodriguez, J. Chem. Technol. Biotechnol., 2008, 83, 13231338.

4 S.S. Lin, M.D. Gurol, Environ. Sci. Technol., 1998, 32, 1417-1423.

5 F. Haber, J. Weiss, Proc. R. Soc. London. Ser. A - Math. Phys. Sci., 1934, 147, 332-351.

6 S. Navalon, M. Alvaro and H. Garcia, Appl. Catal. B Environ., 2010, 99, 1-26.

7 Y. Zhu, R. Zhu, Y. Xi, J. Zhu, G. Zhu and H. He, Appl. Catal. B Environ., 2019, 255, 117739.

8 H. Aghdasinia, A. Khataee, M. Sheikhi and P. Takhtfiroozeh, Environ. Prog. Sustain. Energy, 2017, 36, $1039-1048$.

9 H. Aghdasinia, R. Bagheri, B. Vahid and A. Khataee, Environ. Technol. (United Kingdom), 2016, 37, $2703-2712$.

10 M. Lu, Y. Yao, L. Gao, D. Mo, F. Lin and S. Lu, Water. Air. Soil Pollut., 2015, 226, 87.

11 C. di Luca, P. Massa, J. M. Grau, S. G. Marchetti, R. Fenoglio and P. Haure, Appl. Catal. B Environ., 2018, 237, 11101123.

12 Y. Yan, X. Wu and H. Zhang, Sep. Purif. Technol., 2016, 171, 52-61.

13 J. A. Melero, F. Martínez, J. A. Botas, R. Molina and M. I. Pariente, Water Res., 2009, 43, 4010-4018.

14 F. Martínez, J. A. Melero, J. Á. Botas, M. Isabel Pariente and R. Molina, Ind. Eng. Chem. Res., 2007, 46, 4396-4405.

15 Y. Yu, H. Wei, L. Yu, W. Wang, Y. Zhao, B. Gu and C. Sun, Environ. Technol. (United Kingdom), 2016, 37, $153-162$.

16 Y. Shao and H. Chen, Chem. Eng. Res. Des., 2018, 132, 57-68.

17 H. Huang, H. Zhang and Y. Yan, J. Hazard. Mater., 2021, 407, 124371.

18 F. Liu, H. Zhang and Y. Yan, Sep. Purif. Technol., 2020, 241, 116717.

19 M. Zheng, Y. Bai, H. Han, Z. Zhang, C. Xu, W. Ma and W. Ma, J. Clean. Prod., 2021, 280, 124451.

20 F. Duarte, V. Morais, F. J. Maldonado-Hódar and L. M. Madeira, Chem. Eng. J., 2013, 232, 34-41.

21 Y. Qiu, Q. Zhang, Z. Wang, B. Gao, Z. Fan, M. Li, H. Hao, X. Wei and M. Zhong, Sci. Total Environ., 2021, 758, 143584.

22 Y. Wu, H. Zhang and Y. Yan, Chem. Eng. J., 2020, 380, 122466

23 I. Mesquita, L. C. Matos, F. Duarte, F. J. Maldonado-Hódar, A. Mendes and L. M. Madeira, J. Hazard. Mater., 2012, 237-238, 30-37.

24 J. A. Botas, J. A. Melero, F. Martínez and M. I. Pariente, Catal. Today, 2010, 149, 334-340.

25 G. Satishkumar, M. V. Landau, T. Buzaglo, L. Frimet, M. Ferentz, R. Vidruk, F. Wagner, Y. Gal and M. Herskowitz, Appl. Catal. B Environ., 2013, 138-139, 276-284.

26 F. Martínez, R. Molina, M. I. Pariente, J. A. Siles and J. A. Melero, Catal. Today, 2017, 280, 176-183.

27 J. M. Tatibouët, E. Guélou and J. Fournier, Top. Catal., 2005, 33, 225-232.

28 S. Queirós, V. Morais, C. S. D. Rodrigues, F. J. Maldonado-Hódar and L. M. Madeira, Elsevier, 2015, 141, $235-245$.

29 Y. Yan, S. Jiang and H. Zhang, Sep. Purif. Technol., 2014, 133, 365-374.

30 R. Matta, K. Hanna and S. Chiron, Sci. Total Environ., 2007, 385, 242-251.

31 K. Hanna, T. Kone and G. Medjahdi, Catal. Commun., 2008, 9, 955-959.

32 M. Munoz, Z. M. de Pedro, J. A. Casas and J. J. Rodriguez, Appl. Catal. B Environ., 2015, 176-177, $249-265$.

33 P. Bautista, A. F. Mohedano, J. A. Casas, J. A. Zazo and J. J. Rodriguez, J. Chem. Technol. Biotechnol., 2011, 86, 497504.

34 M. Munoz, Z. M. de Pedro, N. Menendez, J. A. Casas and J. J. Rodriguez, Appl. Catal. B Environ., 2013, 136-137, 218224.

35 H. Lim, J. Lee, S. Jin, J. Kim, J. Yoon and T. Hyeon, Chem. Commun., 2006, 463-465.

36 A. L. T. Pham, C. Lee, F. M. Doyle and D. L. Sedlak, Environ. Sci. Technol., 2009, 43, 8930-8935.

37 S. H. Yoo, D. Jang, H. I. Joh and S. Lee, J. Mater. Chem. A, 2017, 5, 748-755.

38 J. K. Sun and Q. Xu, Energy Environ. Sci., 2014, 7, 2071-210

39 M. Angamuthu, G. Satishkumar and M. V. Landau, Microporous Mesoporous Mater., 2017, 251, 58-68.

40 A. Mani, T. Kulandaivellu, S. Govindaswamy and A. M. Mohan, Environ. Sci. Pollut. Res., 2018, 25, 20419-20429.

41 Manju, P. Kumar Roy, A. Ramanan and C. Rajagopal, Mater. Lett., 2013, 106, 390-392.

42 G. P. Karayannidis, A. P. Chatziavgoustis and D. S. Achilias, Adv. Polym. Technol., 2002, 21, 250-259.

43 H. Y. Mu, F. T. Li, X. T. An, R. H. Liu, Y. L. Li, X. Qian and Y. Q. Hu, Phys. Chem. Chem. Phys., 2017, 19, $9392-9401$.

44 S. H. Lo, D. Senthil Raja, C. W. Chen, Y. H. Kang, J. J. Chen and C. H. Lin, Dalt. Trans., 2016, 45, 9565-9573.

45 J. Ren, X. Dyosiba, N. M. Musyoka, H. W. Langmi, B. C. North, M. Mathe and M. S. Onyango, Int. J. Hydrogen Energy, 2016, 41, 18141-18146.

46 W. P. R. Deleu, I. Stassen, D. Jonckheere, R. Ameloot and D. E. De Vos, J. Mater. Chem. A, 2016, 4, 9519-9525.

47 S. Hou, Y. N. Wu, L. Feng, W. Chen, Y. Wang, C. Morlay and F. Li, Dalt. Trans., 2018, 47, 2222-2231.

48 X. Guo, Y. Deng, B. Tu and D. Zhao, Langmuir, 2010, 26, 702-708. 
49 L. Zhou, L. R. Enakonda, Y. Saih, S. Loptain, D. Gary, P. Del-Gallo and J. M. Basset, ChemSusChem, 2016, 9, 12431248.

50 M. Wang, S. Cheng, G. Dang, F. Min, H. Li, Q. Zhang and J. Xie, Int. J. Electrochem. Sci., 2017, 12, 6292-6303.

51 H. Zhang, X. Sun, X. Huang and L. Zhou, Nanoscale, 2015, 7, 3270-3275.

52 Y. Qin, J. Yuan, L. Zhang, B. Zhao, Y. Liu, Y. Kong, J. Cao, F. Chu, Y. Tao and M. Liu, Small, 2016, 12, 2549-2553.

53 W. Wei, S. Yang, H. Zhou, I. Lieberwirth, X. Feng and K. Müllen, Adv. Mater., 2013, 25, 2909-2914.

54 S. Wang, Q. Jiao, X. Liu, Y. Xu, Q. Shi, S. Yue, Y. Zhao, H. Liu, C. Feng and D. Shi, ACS Sustain. Chem. Eng., 2019, 7, 7004-7013.

55 G. A. Castillo Rodriguez, G. G. Guillen, M. I. Mendivil Palma, T. K. Das Roy, A. M. Guzman Hernandez, B. Krishnan and S. Shaji, Int. J. Appl. Ceram. Technol., 2015, 12, 34-43.

56 B. Wang, J. J. Yin, X. Zhou, I. Kurash, Z. Chai, Y. Zhao and W. Feng, J. Phys. Chem. C, 2013, 117, 383-392.

57 H. W. Tien, Y. L. Huang, S. Y. Yang, J. Y. Wang and C. C. M. Ma, Carbon N. Y., 2011, 49, 1550-1560.

58 R. Grau-Crespo, A. Y. Al-Baitai, I. Saadoune and N. H. De Leeuw, J. Phys. Condens. Matter, 2010, 22, 255401.

59 J. P. Jacobs, A. Maltha, J. G. H. Reintjes, J. Drimal, V. Ponec and H. H. Brongersma, J. Catal., 1994, 147, $294-300$.

60 M. Ferentz, M. V. Landau, R. Vidruk and M. Herskowitz, Catal. Today, 2015, 241, 63-72.

61 P. Suraj, V. Kumar, C. Thakur and P. Ghosh, J. Environ. Chem. Eng., 2018, 7, 102859. 